\title{
The global 3-D distribution of tropospheric aerosols as characterized by CALIOP
}

\author{
D. M. Winker ${ }^{1}$, J. L. Tackett ${ }^{2}$, B. J. Getzewich ${ }^{2}$, Z. Liu ${ }^{2}$, M. A. Vaughan ${ }^{1}$, and R. R. Rogers ${ }^{1}$ \\ ${ }^{1}$ NASA Langley Research Center, MS/475,Hampton, VA, USA \\ ${ }^{2}$ SSAI, Hampton, VA, c/o NASA LaRC, MS/475, USA
}

Correspondence to: D. M. Winker (david.m.winker@nasa.gov)

Received: 1 August 2012 - Published in Atmos. Chem. Phys. Discuss.: 21 September 2012

Revised: 8 February 2013 - Accepted: 27 February 2013 - Published: 25 March 2013

\begin{abstract}
The CALIOP lidar, carried on the CALIPSO satellite, has been acquiring global atmospheric profiles since June 2006. This dataset now offers the opportunity to characterize the global 3-D distribution of aerosol as well as seasonal and interannual variations, and confront aerosol models with observations in a way that has not been possible before. With that goal in mind, a monthly global gridded dataset of daytime and nighttime aerosol extinction profiles has been constructed, available as a Level 3 aerosol product. Averaged aerosol profiles for cloud-free and all-sky conditions are reported separately. This 6-yr dataset characterizes the global 3-dimensional distribution of tropospheric aerosol. Vertical distributions are seen to vary with season, as both source strengths and transport mechanisms vary. In most regions, clear-sky and all-sky mean aerosol profiles are found to be quite similar, implying a lack of correlation between high semi-transparent cloud and aerosol in the lower troposphere. An initial evaluation of the accuracy of the aerosol extinction profiles is presented. Detection limitations and the representivity of aerosol profiles in the upper troposphere are of particular concern. While results are preliminary, we present evidence that the monthly-mean CALIOP aerosol profiles provide quantitative characterization of elevated aerosol layers in major transport pathways. Aerosol extinction in the free troposphere in clean conditions, where the true aerosol extinction is typically $0.001 \mathrm{~km}^{-1}$ or less, is generally underestimated, however. The work described here forms an initial global 3-D aerosol climatology which we plan to extend and improve over time.
\end{abstract}

\section{Introduction}

Aerosols have a variety of effects on Earth's climate, including effects on cloud properties and precipitation as well as direct radiative influences. The nature of these effects depends strongly on the vertical distribution of the aerosol. Warming effects of absorbing aerosol are amplified when they are located above bright clouds and the atmospheric lifetime of aerosol is much greater when it resides in the free troposphere than in the planetary boundary layer. Longer lifetime allows aerosol to be transported farther from its sources, affecting the geographic pattern of aerosol impacts. The global vertical distribution of tropospheric aerosol is especially valuable for evaluation of global aerosol models because it is a signature of the combined effects of aerosol emissions, the strength of vertical lifting and exchange, atmospheric transport patterns, and removal processes.

Recent studies have shown a large diversity in the distributions of aerosol predicted by current global aerosol models (Kinne et al., 2006; Textor et al., 2006; Huneeus et al., 2011). This diversity has been identified as being due more to uncertainties in the simulation of aerosol processes such as transport and removal, than in the realism of the aerosol precursor emissions used by the models (Textor et al., 2006). While there is a reasonable consistency in prediction of column aerosol optical depth (AOD), the models were found to have large disagreements in the vertical distributions of aerosol. The degree of intermodel agreement seen for AOD is due in part to the availability of global AOD measurements from satellites which have been used for more than a decade to evaluate and improve models. But, until relatively recently, 
there has been no similar global observation of the vertical distribution of aerosol throughout the troposphere.

The CALIOP lidar, carried on the CALIPSO satellite, has been acquiring global aerosol and cloud profile data since June 2006 (Winker et al., 2010) between latitudes of $82^{\circ} \mathrm{S}$ and $82^{\circ} \mathrm{N}$. CALIPSO flies as part of the A-train constellation of satellites, and so is in a sun synchronous orbit with an equator crossing time near 2 p.m. and a 16-day orbit repeat cycle. Several previous studies have used CALIOP data to examine seasonal and regional-mean aerosol vertical distributions for the purpose of model evaluation. Yu et al. (2010) compared seasonal variations of the vertical distributions of aerosol extinction in selected regions derived from CALIOP observations in clear skies with aerosol estimates from the GOCART model (Chin et al., 2002). This study, based on CALIOP Version 2 data from June 2006 to November 2007, found significant differences in modeled and observed aerosol extinction profiles. The study found a need for improvements in both the models and in the CALIOP aerosol retrievals. Several limitations in the Version 2 CALIOP aerosol data were noted, including uncertainties due to finite detection sensitivity of the CALIOP instrument, uncertainties associated with selection of lidar ratios, and misclassifications of features. More recently, Koffi et al. (2012) derived monthly regionally-averaged aerosol extinction profiles over the period 2007-2009 from CALIOP Version 3 data for use in a major AeroCom model intercomparison. This study noted significant improvements in the Version 3 data, but still expressed concerns regarding detection limits and general accuracy of CALIOP aerosol extinction data.

In this paper we describe the CALIOP Level 3 Aerosol Profile product, a monthly, global gridded dataset of aerosol extinction profiles, constructed from CALIOP Version 3 aerosol data, which has been developed to provide a threedimensional view of the global distribution of atmospheric aerosols. CALIOP is a nadir-viewing instrument and only acquires measurements along the satellite ground-track. Thus, daily geographical sampling is very limited compared to a broad-swath sensor such as MODIS (Remer et al., 2008). However, by aggregating statistics on monthly basis, a representative description of the 3-D distribution of aerosol is obtained.

In Sect. 2 we briefly describe the CALIOP aerosol retrieval approach and Level 2 data products. Section 3 summarizes the contents of the Level 3 aerosol profile product and the method used to construct it. Section 4 discusses general characteristics of the global aerosol dataset and then Sect. 5 examines seasonal variability of the aerosol vertical distribution. Finally, Sect. 6 provides an initial evaluation of the accuracy of the monthly mean extinction profiles.

\section{CALIOP aerosol products}

The Cloud-Aerosol Lidar with Orthogonal Polarization (CALIOP) instrument acquires lidar backscatter profiles at $532 \mathrm{~nm}$ and $1064 \mathrm{~nm}$, including parallel and perpendicular polarized returns at $532 \mathrm{~nm}$. Profiles are sampled at a vertical resolution of $30 \mathrm{~m}$ below an altitude of $8.2 \mathrm{~km}$ and $60 \mathrm{~m}$ between $8.2 \mathrm{~km}$ and $20.2 \mathrm{~km}$. After calibration and range registration, cloud and aerosol layers are identified and aerosol extinction is retrieved at $532 \mathrm{~nm}$ and $1064 \mathrm{~nm}$, using estimated lidar ratios. Dense clouds can be detected in single-shot profiles but detection of aerosol layers usually requires averaging of multiple lidar shots. Clouds are identified and removed before averaging to avoid cloud contamination of the aerosol data. To detect tenuous aerosol layers but also avoid cloud contamination of the aerosol data, a multi-scale averaging scheme is used to detect both weakly and strongly scattering clouds, which are then removed before further horizontal averaging (Vaughan et al., 2009; Winker et al., 2009). Cloud and aerosol layers are detected using a threshold technique applied to profiles of attenuated scattering ratio, $\operatorname{SR}(z)$. After layers are detected, a discrimination algorithm is applied to separate cloud and aerosol (Liu et al., 2009), except for layers detected in single-shot $(1 / 3 \mathrm{~km})$ profiles which are assumed to be cloud, followed by an algorithm which classifies the aerosol type. Each aerosol type has a lidar ratio, $S_{\mathrm{a}}$ (the ratio of aerosol 180-backscatter and extinction), associated with it in a lookup table. This estimated lidar ratio is later used in the retrieval of aerosol extinction (Young and Vaughan, 2009).

Aerosol extinction retrievals are only performed within detected layers, as the CALIOP signal-to-noise ratio (SNR) does not permit retrievals in clear air at the spatial resolution of the Level 2 products. Detection thresholds are defined in terms of $532 \mathrm{~nm}$ scattering ratio and are adjusted according to altitude, solar background illumination, and averaging resolution (Vaughan et al., 2009). Because the detection thresholds are defined in terms of backscattering, the threshold in terms of aerosol extinction depends on the aerosol lidar ratio, $S_{\mathrm{a}}$. For the six aerosol types defined in the CALIOP retrieval (Dust, Polluted Dust, Marine, Clean Continental, Pollution, and Biomass Burning), $S_{\mathrm{a}}$ varies from 20-70 sr (Omar et al., 2009). Figure 1 shows the detection thresholds used for marine aerosol and smoke, which span the range of $S_{\mathrm{a}}$ used in the Version 3 retrieval. Curves depict detection sensitivity during day and night for horizontal averaging of $5 \mathrm{~km}$ and $80 \mathrm{~km}$. The Day-Low curves represent the sensitivity for low solar background conditions such as cloud-free scenes over ocean. Higher thresholds are used during daytime than at night because SNR is reduced by solar background illumination, so weakly scattering layers which are detected at night may be missed during daytime. Above an altitude of $8.2 \mathrm{~km}$, two $30-\mathrm{m}$ vertical bins are averaged (onboard the satellite) to $60 \mathrm{~m}$. This improves the SNR and thresholds are decreased accordingly. The lidar signal is partially attenuated by each layer it passes through. The retrieval algorithm 

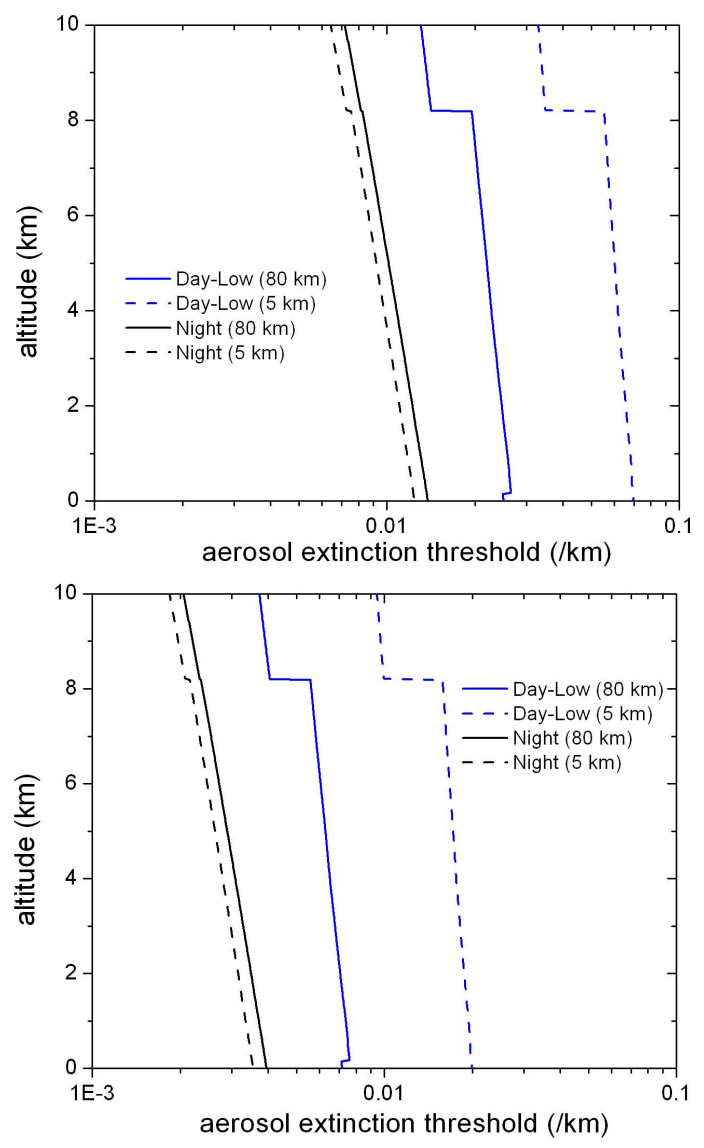

Fig. 1. Detection thresholds used in Level 2 data processing, in terms of $532 \mathrm{~nm}$ aerosol extinction. Upper panel: smoke $(S=70 \mathrm{sr})$; Lower panel: marine $(S=20 \mathrm{sr})$.

estimates and corrects the signal below the cloud for this attenuation (Vaughan et al., 2009). Because the lidar ratio of smoke is much larger than that of marine aerosol, lower levels of aerosol extinction can be detected for marine aerosol. Because of signal noise, in practice the extinction retrieved from detected layers varies somewhat around these thresholds.

Accuracy of $532 \mathrm{~nm}$ AOD derived from CALIOP aerosol extinction retrievals has been investigated in several studies. Kittaka et al. (2011) compared CALIOP Version 2 AOD with co-located MODIS AOD and Redemann et al. (2012) compared both CALIOP Version 2 and Version 3 AOD against MODIS. Based on subsets of co-located CALIOP and MODIS AOD retrievals, both studies found monthlymean AOD agreed to within 0.03 and 0.04. CALIOP AOD has been found to be generally lower than MODIS, although there is evidence for regional biases in both MODIS and CALIOP retrievals. Several studies have noted that MODIS AOD increases as the environment becomes cloudier (Loeb and Smith, 2005; Zhang and Reid, 2006; Kittaka et al., 2011). In general, the studies of co-located CALIOP and MODIS
AOD concluded that global- and zonal-mean differences between the two sensors are roughly within the envelope of the MODIS expected uncertainty, with larger differences over land than over ocean. More recently, Koffi et al. (2012) have compared CALIOP Version 2 and Version 3 AOD with MODIS Collection 5. Based on a comparison of regional averages, rather than co-located samples, they report significant improvement in agreement with MODIS AOD in going from CALIOP Version 2 to Version 3 data. Regionalmean differences between CALIOP and MODIS AOD were found to fall within the MODIS expected uncertainty in 6 of 13 regions, while CALIOP AOD was significantly higher than MODIS in 4 regions and significantly lower in the other 3 regions. Perhaps coincidentally, the four regions where CALIOP AOD was higher were all continental and the regions where CALIOP AOD was lower were maritime regions dominated by pollution or smoke.

\section{Construction of gridded profiles}

CALIOP Level 2 data contain curtains of retrieved profile data along the CALIPSO track. Level 2 aerosol products contain height-resolved geophysical parameters such as aerosol backscatter, extinction, depolarization, and results of the aerosol type classification. Uncertainty estimates are included for each retrieved parameter, along with a number of data quality flags.

CALIOP Version 3 Level $2532 \mathrm{~nm}$ aerosol extinction data are aggregated onto a global $2^{\circ} \times 5^{\circ}$ latitude-longitude grid. Vertical resolution is $60 \mathrm{~m}$, from -0.5 to $12 \mathrm{~km}$. Altitude is referenced to mean sea level. Mean extinction profiles are computed for dust-only and for all aerosol species. CALIOP retrieves aerosol below optically thin cloud as well as in clear skies and above clouds. Monthly-mean extinction profiles are computed for four conditions: daytime all-sky and cloudfree, and nighttime all-sky and cloud-free.

Several quality control flags contained in the Level 2 files are used to screen the data before averaging. A brief summary is provided here, with more details provided in the Appendix.

A Cloud Aerosol Discrimination (CAD) score is used to indicate the confidence in the classification of layers as either aerosol or cloud (Liu et al., 2009). To avoid low-confidence aerosol layers which might be the result of detection artifacts, only layers with CAD scores inclusive of -20 and -100 are used. The Extinction QC flag indicates the type of retrieval performed on each layer and flags problematic retrievals. Only aerosol layers with values of $0,1,18$ and 16 are accepted. Each aerosol extinction value in the Level 2 products has an associated uncertainty (Young et al. 2013). A sample with an extinction uncertainty of $99.9 \mathrm{~km}^{-1}$ indicates the retrieval has become unreliable. Because the retrieval starts at the top of the atmosphere and proceeds downward, samples 
with uncertainty of $99.9 \mathrm{~km}^{-1}$ and all samples at lower altitudes in the profile are removed.

In addition to screening based on quality flags, several other screening steps are also applied. The most important of these is a test for misclassified cloud. Weakly scattering edges of ice clouds are sometimes misclassified as aerosol by the Cloud Aerosol Discrimination algorithm, producing a spurious enhancement of aerosol loading in the upper troposphere. Therefore, individual layers identified as aerosol which are not immediately adjacent to another aerosol layer but adjacent to an ice cloud are assumed to be misclassified cloud and are ignored. This test is applied only to aerosol layers above $4 \mathrm{~km}$ altitude. Further details on data screening are provided in Appendix A.

Figure 2 compares a mean cloud-free profile before and after screening. Horizontal bars indicate estimated RMS errors. Note there are small changes in the mean profile at some altitudes, but large decreases in the error bars. Aerosol was observed between 3.5 and $4 \mathrm{~km}$ on just one orbit, resulting in large error bars. The aerosol layer between $9-10 \mathrm{~km}$ in the left panel is due to cirrus misclassified as aerosol, and is removed by the test for isolated aerosol layers adjacent to ice cloud. Because retrieval errors propagate downward, the lower parts of the profile always have higher uncertainty and contain more retrieval artifacts. Changes in the lowest $2 \mathrm{~km}$ of the profile are due primarily to the Ext_QC and Unc_532 tests, which tend to remove data with retrieval artifacts.

The current CALIOP algorithms only retrieve aerosol within detected layers, and range bins outside detected layers are assigned fill values. When profiles are averaged, fill values representing clear air are assigned an extinction value of $0.0 \mathrm{~km}^{-1}$. This results in an underestimate of mean extinction and there is a possibility that this underestimate is significant. This issue is discussed in Sect. 6 and is being addressed in initial validation studies.

Range bins within cloud or where the signal is completely attenuated, such as below opaque layers, are ignored when averaging. Cloudy samples are identified using cloud mask information contained in the CALIOP Level 2 products. Likewise, when surface elevation varies within a grid cell, averaging at each altitude is based only on samples located above the Earth surface. Detection of aerosol layer bases can be difficult and the layer detection algorithm sometimes places the aerosol layer base well above the Earth surface. Averaging "clear air" (with extinction $=0$ ) below the lowest detected aerosol layer will cause the profile to be biased low near the surface. To avoid underestimating the lowest part of the aerosol profile, when the base of the lowest aerosol layer is above the local surface but lower than $2.46 \mathrm{~km}$, the "clear air" samples between the surface and the aerosol layer are ignored when averaging. The $2.46 \mathrm{~km}$ threshold was chosen to be consistent with the altitude threshold used in the aerosol "base extension" algorithm implemented in Version 3. This choice is somewhat arbitrary and a study will be performed
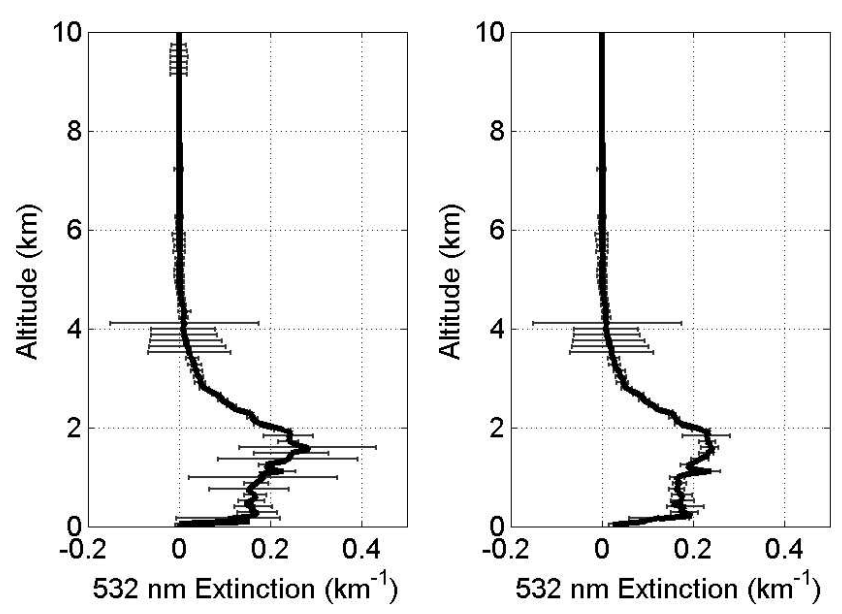

Fig. 2. Average $532 \mathrm{~nm}$ extinction profiles (day and night combined), August $2007,35-39^{\circ} \mathrm{N}, 75-80^{\circ} \mathrm{W}$. Left panel: unscreened cloud-free profile; Right panel: after screening applied.

to see if the shape of the extinction profiles is sensitive to the value of this altitude threshold.

Some of the details of the screening and averaging procedures used here are different than in either Yu et al. (2010) or Koffi et al. (2012). In particular, our decision to ignore "clear" air near the surface during averaging tends to increase the magnitude of extinction near the surface relative to Koffi et al. (2012). Impacts of the screening approach adopted will be addressed in a sensitivity analysis now in preparation.

\section{Global patterns of aerosol distribution}

The emphasis in this paper is on the vertical distribution of aerosol, as that is the most unique new information provided by CALIOP. We begin, however, with an examination of global AOD to show general characteristics of the data. Figure 3 compares 5-yr mean global distributions of CALIOP $532 \mathrm{~nm}$ AOD computed from the four different types of profiles: all-sky daytime, all-sky nighttime, cloud-free daytime, and cloud-free nighttime. CALIOP provides the first global nighttime observations of aerosol. The patterns of AOD distribution are similar between all four maps, although the magnitude varies somewhat. The solar background reduces the aerosol detection sensitivity during daytime (Fig. 1) resulting in a somewhat smaller column AOD and tendency to miss tenuous aerosol layers. Monthly-mean patterns of allsky and cloud-free column AOD tend to be very similar. Allsky AOD includes regions where cloud tends to cover lowlaying aerosol, so mean AOD tends to be reduced relative to cloud-free conditions. The larger number of all-sky samples (relative to cloud-free) improves the sampling statistics and generally produces smoother looking distributions, although that is not apparent in these multi-year means. 

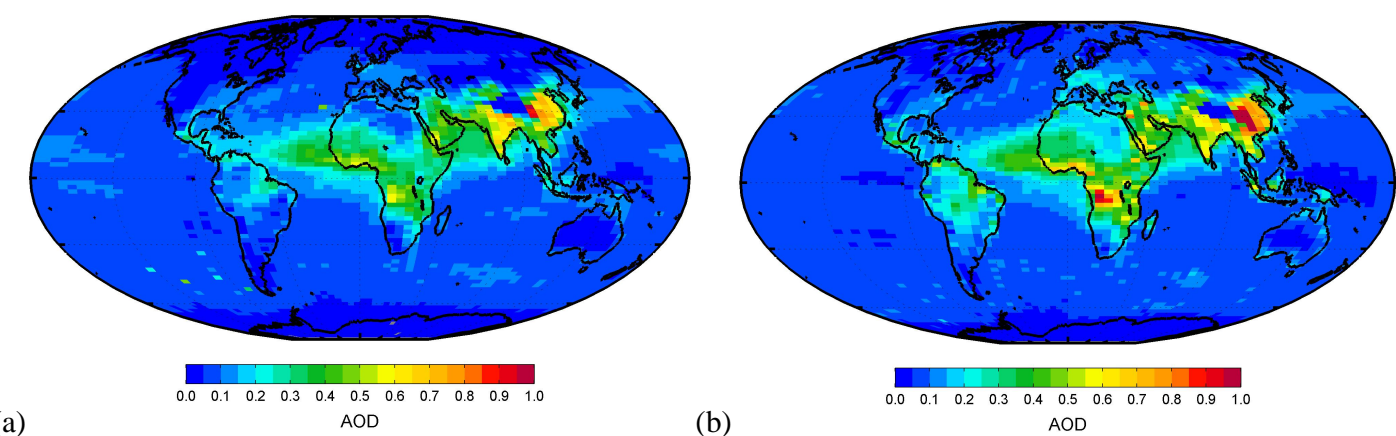

(a)

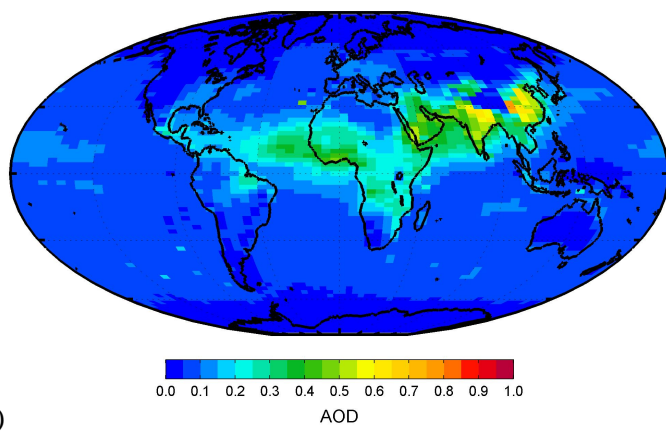

(b)

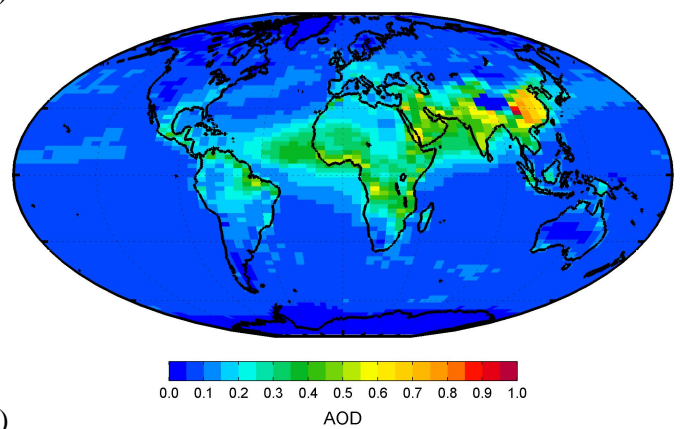

Fig. 3. Mean 532 nm AOD, January 2007-December 2011: (a) cloud-free, daytime; (b) cloud-free, nighttime; (c) all-sky, daytime; (d) all-sky, nighttime.

Some of the differences are due to differences in sampling. Cloud-free AODs are weighted toward regions of less frequent cloudiness, and day and night orbits tend to sample different geographical areas due to the orbit pattern. Aerosol concentrations near source regions can vary diurnally, particularly near sources of smoke and dust. Due to the sparse sampling, a large but sporadic and regional aerosol event will not be observed in a consistent way during both day and night and can weight the statistics of an entire month. Additional diurnal differences can be attributed to the behavior of the retrieval algorithms. The layer detection algorithm is tuned differently for day and night (see Fig. 1), to account for differences in SNR, and many of the retrieval algorithms exhibit subtle differences in their behavior during daytime and nighttime. Nevertheless, all four global distributions are similar and show the expected features: major source regions in Africa, India, and eastern China, with transport westward into the Atlantic Ocean from Africa and from Asia into the north Pacific Ocean (Remer et al., 2008; Kinne et al., 2006).

Figure 4 shows time series of monthly global mean $532 \mathrm{~nm}$ AOD for the four types of profiles. To facilitate comparison with previous results, data is separated into over-land and over-water. A clear seasonal variation is evident, with a larger magnitude of variation over land than over ocean. Linear fits to the de-seasonalized timeseries of daytime, cloudfree AOD give trends of -0.00042 and -0.0080 per decade for global ocean and global land, respectively. Neither of these trends is statistically significant. The much larger trend for global land is due to large anomalies during 2010-2011
Table 1. Global mean $532 \mathrm{~nm}$ AOD from monthly time series, June 2006-December 2011.

\begin{tabular}{lcc}
\hline & Global Ocean & Global Land \\
\hline cloud-free, day & 0.093 & 0.18 \\
cloud-free, night & 0.087 & 0.21 \\
All-sky, day & 0.086 & 0.15 \\
All-sky, night & 0.098 & 0.19 \\
\hline
\end{tabular}

and the relatively short length of the timeseries. The longterm stability of the global ocean AOD is indicative of the stable calibration achieved using the upper atmosphere as a reference target (Winker et al., 2009). Monthly mean AOD derived from the four different types of extinction profiles are offset, but track each other reasonably well. Mean AOD for global ocean and global land is listed in Table 1. Diurnal differences are much larger over land than over ocean, and are slightly larger for all-sky profiles than for cloud-free. The cloud-free daytime values are the most comparable with multi-year means from Aqua-MODIS. Mean $550 \mathrm{~nm}$ AOD from Aqua-MODIS Collection 5 is 0.19 over land and 0.13 over ocean (Remer et al., 2008). These values can be compared to CALIOP daytime cloud-free AOD, but it should be remembered that the geographical sampling of the two sensors is quite different. In particular, over land, the CALIOP record includes desert regions which are not included in MODIS Collection 5. 

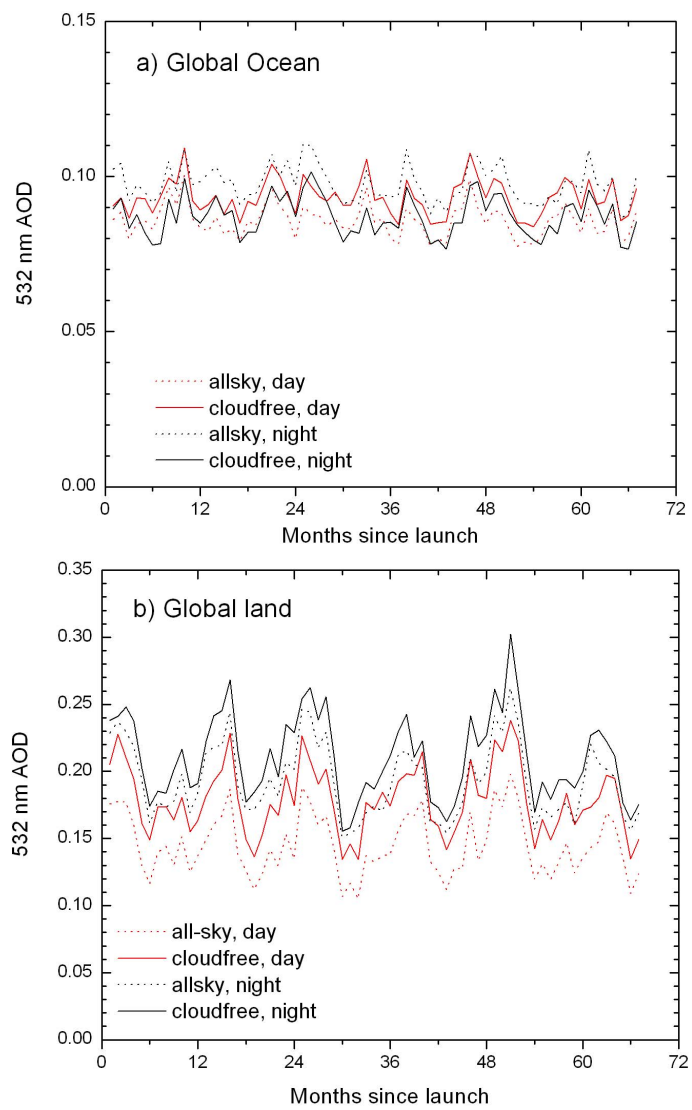

Fig. 4. Monthly-mean $532 \mathrm{~nm}$ AOD time series. (a) Global ocean. (b) Global land.

Small absolute differences in global means between CALIOP and MODIS are probably not too meaningful, as global mean MODIS AOD can vary by more than $20 \%$ depending on how data are aggregated, averaged and weighted (Remer et al., 2008; Levy et al., 2009). Zhang and Reid (2006) found Terra $550 \mathrm{~nm}$ AOD over global oceans was reduced by $12 \%$ after additional quality control procedures were applied, with reductions of as much as $30 \%$ in southern mid-latitudes and the north Pacific.

Use of CALIOP $532 \mathrm{~nm}$ depolarization profiles has been established as a direct and robust means of identifying mineral dust (Omar et al., 2009; Liu et al., 2008). Figure 5 shows the 5-yr mean (2007-2011) of the global distribution of mineral dust, mapping the ratio of dust AOD to total AOD in each column. Irregular mineral dust is classified by CALIOP as either "Dust", meaning pure dust, or "Polluted Dust", meaning dust mixed with smoke or other non-depolarizing aerosol. Here we consider only pure dust, so the fraction of total AOD due to dust shown here is a lower bound. For example, dust mixed into the marine boundary layer is often classified as "polluted dust" or even as "marine" aerosol, thus leading to an underestimate.

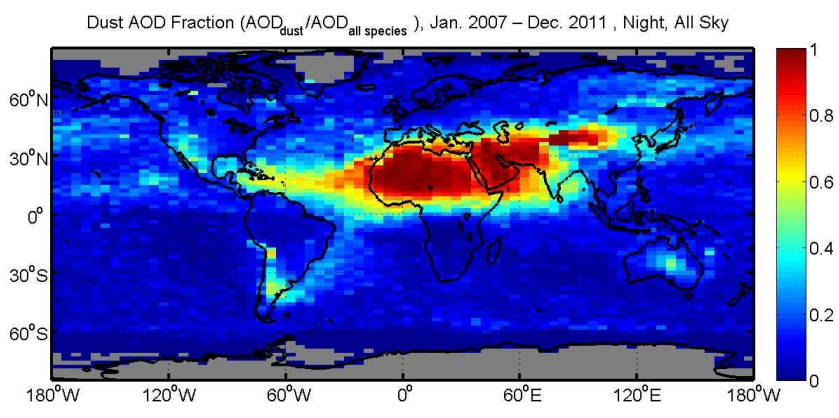

Fig. 5. Mean dust AOD fraction, 2007-2011.

The so-called "dust belt" is clearly evident, extending from the Sahara eastward across Arabia and southwest Asia and into central China. A contrast in dust content between eastern and western US is also seen. Transport of dust from the Sahara westward across the Atlantic Ocean into the Caribbean is ubiquitous. During springtime, Sahara dust is transported as far as northeastern South America (not shown). Seasonal transport of dust from Asia across the northern Pacific is most evident in spring.

Southern Argentina is seen to be a consistent source of dust, except during MAM, with a peak in SON. Dust concentrations in the southeast Atlantic seem to correlate with the concentration of dust in Argentina. In the interior of Australia, dust emissions are seen to be maximum in austral summer and minimum in austral winter. Dust emissions in the Southern Hemisphere are generally much weaker than in Asia and north Africa, however. Dust is consistently evident off the coast of South America in the southwest Atlantic, although this dust only contributes about 0.05 to the total AOD. There is little evidence of transport of Australian dust, and dust transport in the Southern Hemisphere seems to consist primarily of transport from South America.

Dust AOD in remote oceans of the Southern Hemisphere, where no dust is expected, tends to be on the order of 0.01 , indicating that artifacts and errors are small. In particular, little dust is identified between $60-40^{\circ} \mathrm{S}$. The low frequency of dust reported in this cloudy region indicates that misclassification of cloud as dust occurs infrequently.

Figure 6 shows the annual nighttime zonal mean distribution of aerosol extinction. This is the all-sky case but the cloud-free case looks very similar. Dotted lines show altitudes where $63 \%$ and $90 \%$ of the AOD lies below. At mid and high latitudes, aerosol is largely confined to the lowest kilometer of the atmosphere. A maximum in near-surface extinction is seen between $40-60^{\circ} \mathrm{S}$, representing marine aerosol in the southern ocean. Saharan dust is responsible for another near-surface maximum between $0-40^{\circ} \mathrm{N}$, and also the strongest vertical transport. Textor et al. (2006), in an intercomparison study of 15 different global aerosol models, noted a large diversity in the estimated zonal-mean mass concentration distributions. Data such as this can provide much 


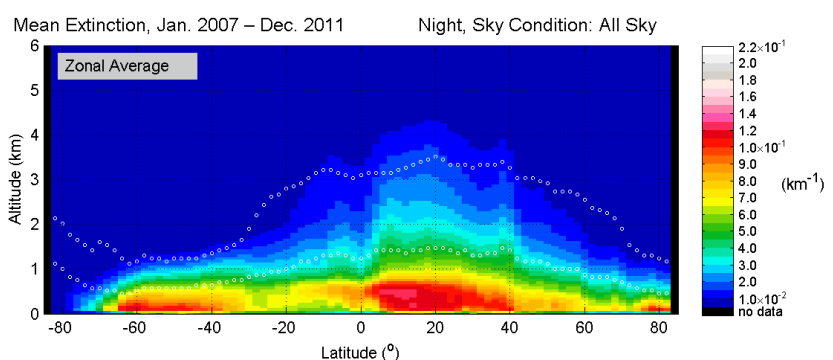

Fig. 6. Zonal mean $532 \mathrm{~nm}$ aerosol extinction $\left(\mathrm{km}^{-1}\right)$, from January 2007 to December 2011, nighttime, all-sky.

stronger tests of model aerosol processes than have been possible before.

Aerosol profiles can exhibit diurnal biases due to improved detection sensitivity at night relative to daytime. Figure 7 shows the ratio of daytime to nighttime zonal mean extinction for JJA. Diurnal biases are small below $1 \mathrm{~km}$, where aerosol loading is relatively high. Daytime zonal mean extinction is biased low by as much as $50 \%$ above $2 \mathrm{~km}$, although zonal mean biases between $10-30^{\circ} \mathrm{N}$, which is dominated by mineral dust from the Sahara, are small at most altitudes.

Somewhat surprisingly, monthly-average cloud-free and all-sky profiles are typically found to be very similar. This was also noted by Koffi et al. (2012). Figure 8a compares summertime cloud-free and all-sky extinction profiles for the eastern United States $\left(31-41^{\circ} \mathrm{N}, 95-75^{\circ} \mathrm{W}\right)$. The shapes of the all-sky and cloud-free profiles are seen to be very similar, with AOD of 0.216 and 0.218 , respectively, even though about $30 \%$ of the all-sky aerosol retrievals come from below clouds. The similarity implies that the occurrence of high clouds is largely uncorrelated with the aerosol loading within the planetary boundary layer (PBL), where most of the aerosol is located. In contrast, Fig. 8b shows multiyear mean profiles over southeast Asia $\left(1-19^{\circ} \mathrm{N}, 90-110^{\circ} \mathrm{E}\right)$ for August, where larger differences are seen. Cloud cover is ubiquitous in this region, with more than 10 times as many retrievals in cloudy columns as in clear-sky. Clear-sky profiles represent a biased sample of both geography and meteorology within the region. In this case, systematic differences are seen between all-sky and clear-sky profiles, suggesting differences in boundary layer structure and in the strength of vertical transport. This example raises cautions about the interpretation and representivity of passive satellite aerosol retrievals, which are restricted to clear-sky regions only, in areas of high cloudiness.

\section{Seasonal vertical distribution}

In this section we examine seasonal variability of the vertical distribution of aerosol. There is little interannual variability in the general patterns so we focus on one year, 2008. To pro-

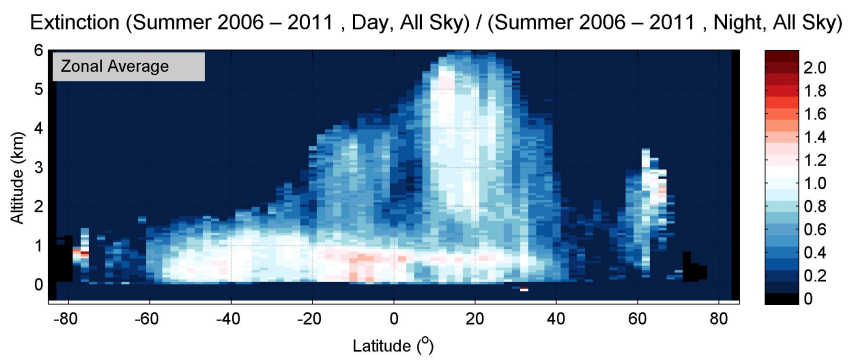

Fig. 7. Ratio of daytime to nighttime zonal mean aerosol extinction: JJA, 2006-2011.
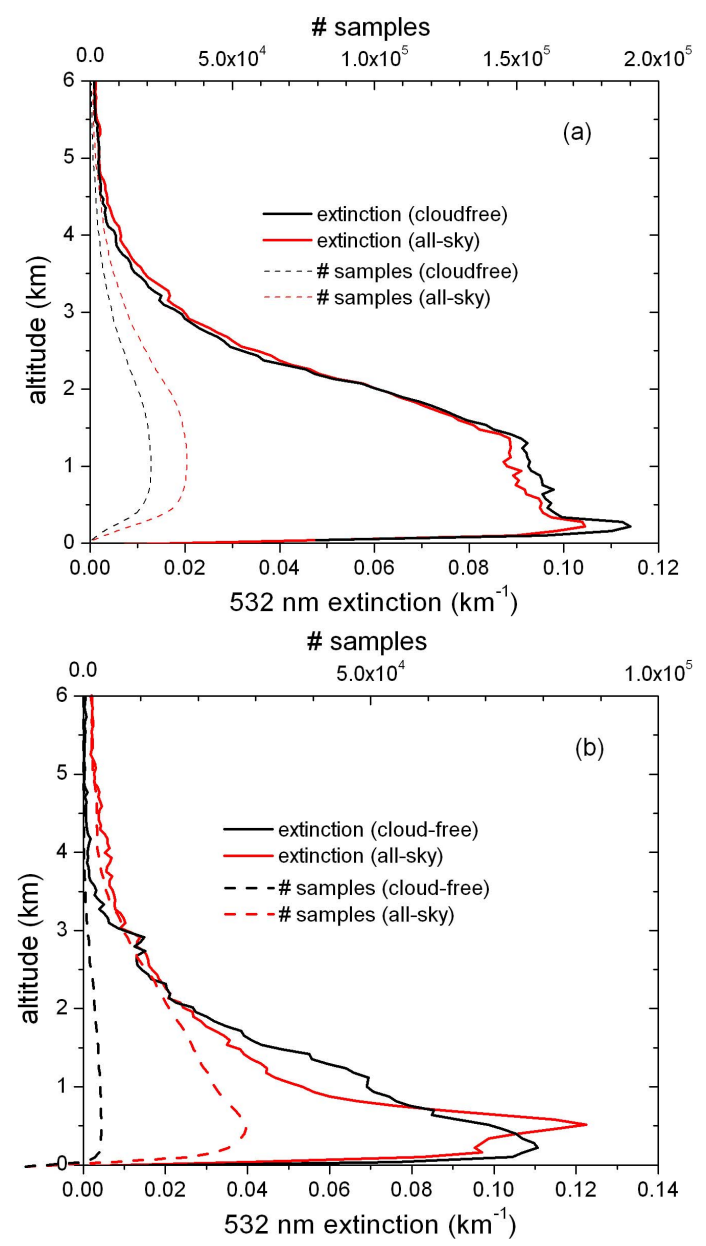

Fig. 8. Mean nighttime profiles. (a) Over eastern US $\left(31-41^{\circ} \mathrm{N}\right.$, 95-75 $\mathrm{W}$ ) during July 2006-2011; (b) over SE Asia (1-19 N, 90$\left.110^{\circ} \mathrm{E}\right)$ during August 2006-2011. Solid lines: $532 \mathrm{~nm}$ aerosol extinction; dashed lines: number of aerosol samples.

vide an overview, Fig. 9 shows the seasonal-mean extinction scale height, $H_{63}$ which corresponds to the altitude at which $63 \%$ of the AOD lies below. This is the same statistic used in Yu et al. (2010). For context, Fig. 10 shows the corresponding seasonal AOD maps, which show seasonal patterns well 
(a)
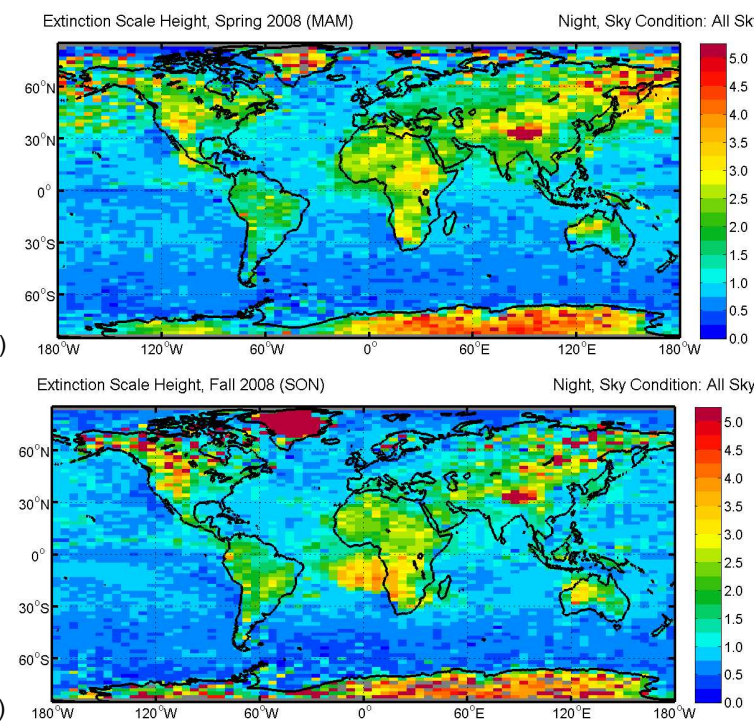

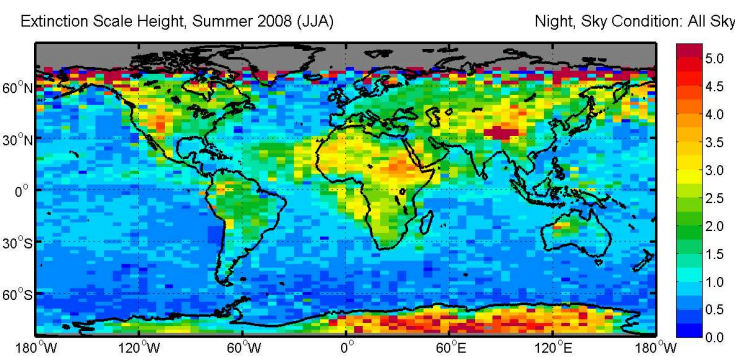

Extinction Scale Height, Winter 2008 (DJF)

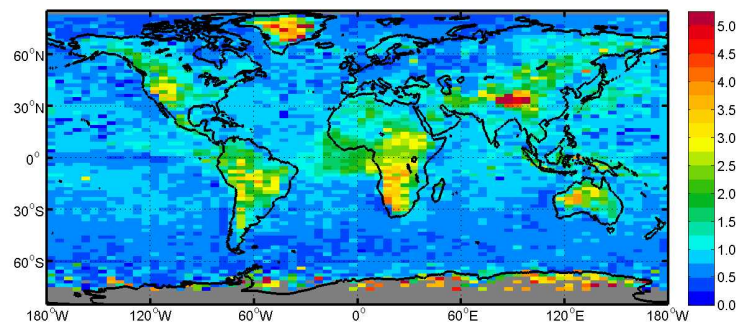

Fig. 9. Seasonal mean $H_{63}$ height metric (km) for 2008, nighttime, all-sky: (a) MAM; (b) JJA; (c) SON; (d) DJF.
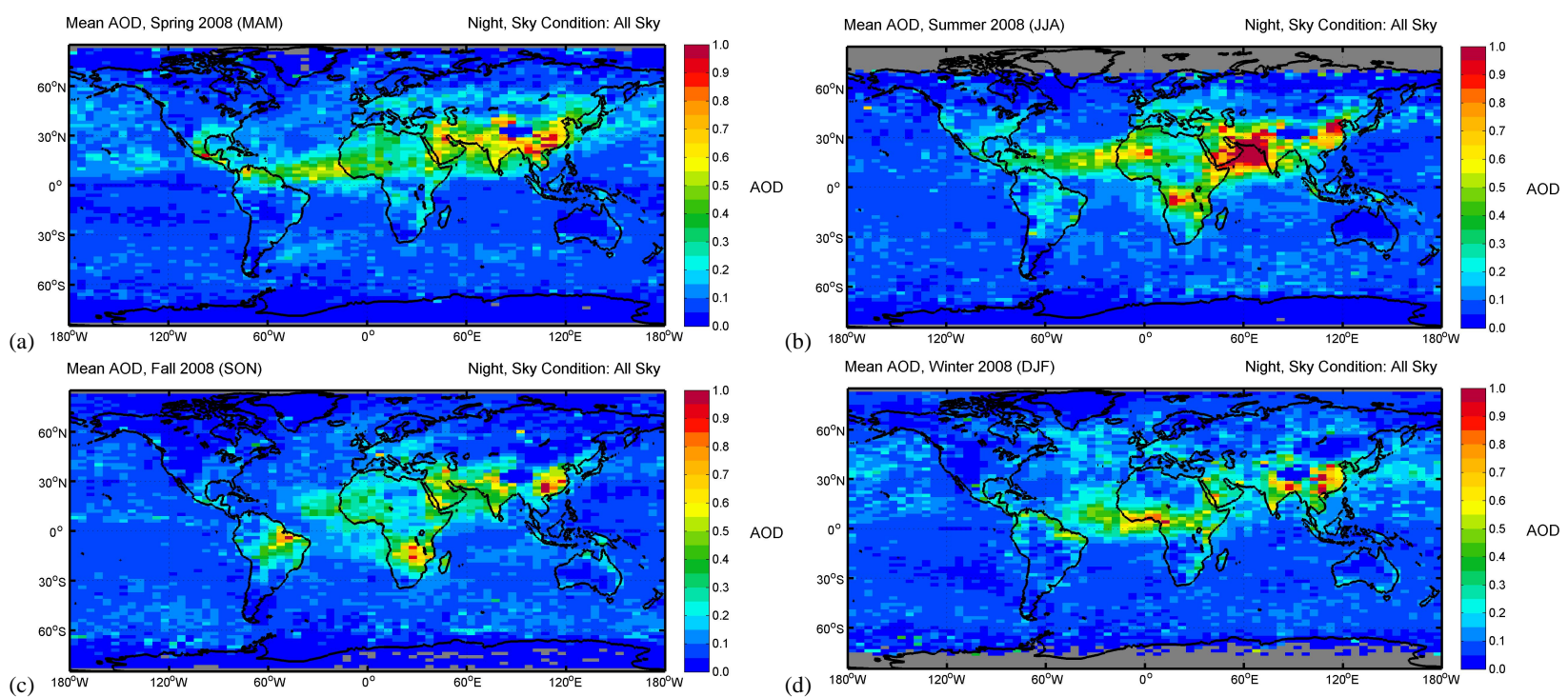

(b)

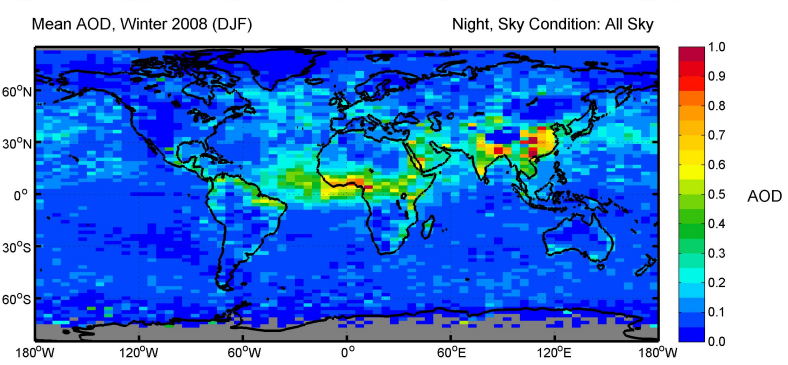

Fig. 10. Seasonal mean AOD for 2008, nighttime, all-sky: (a) MAM; (b) JJA; (c) SON; (d) DJF.

known since the early days of satellite aerosol remote sensing (Husar et al., 1997).

In aerosol source regions the scale height is an indication of the strength of vertical transport. Over oceans, the bulk of the aerosol is confined to the marine boundary layer and large values of $H_{63}$ are indicators of long-range transport of continental aerosol. Turbulent mixing within the PBL tends to spread the aerosol throughout the depth of the atmospheric mixed layer. The strong contrast in scale height between land and ocean is an indication of the expected difference in depth of the marine and continental PBL. $H_{63}$ is referenced to sea level so high values are seen wherever the land surface is elevated, such as the western United States and the Tibetan plateau, where surface elevations range from $3-4 \mathrm{~km}$. High values seen over Antarctica and Greenland are spurious, as these regions are quite clean and very little aerosol is seen above the ice sheets.

Comparison of Figs. 9 and 10 illustrates known characteristics of the transport of mineral dust from the Sahara into the central Atlantic Ocean. There is significant westward transport during all seasons, but during JJA the dust tends to be transported as elevated layers above $2 \mathrm{~km}$ altitude, whereas during DJF the dust primarily occurs at low altitudes. The seasonal progression of smoke from biomass burning can also be seen in Fig. 9. Smoke from burning in equatorial Africa during DJF and MAM is carried into the Gulf of 
(a)

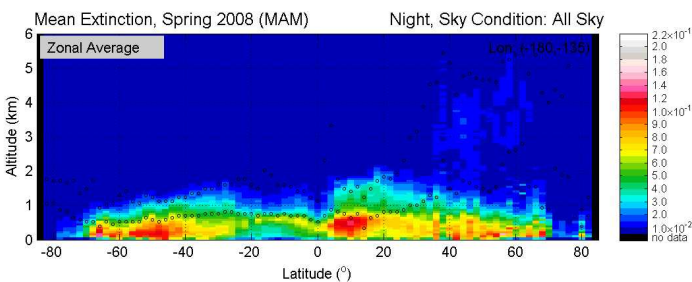

(b)

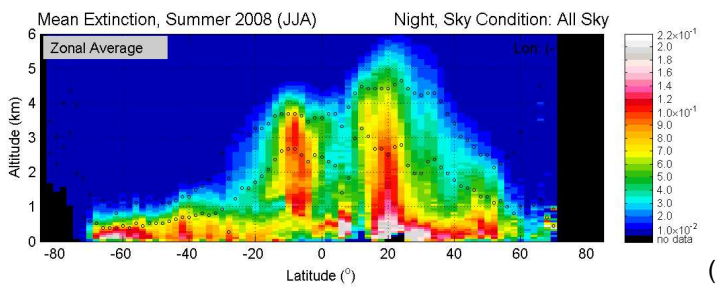

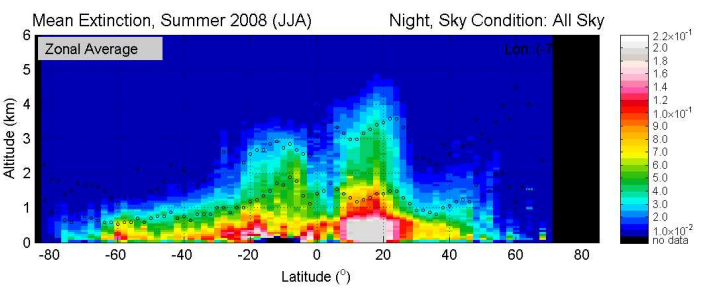

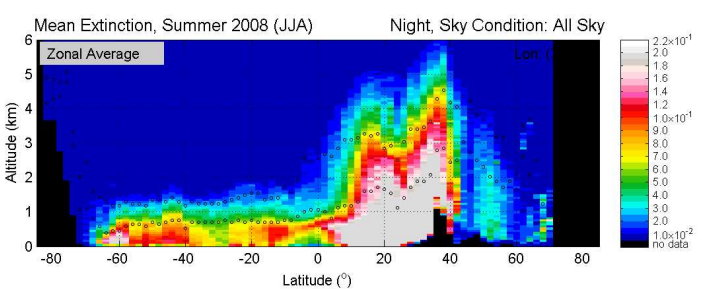

Fig. 11. Regional zonal aerosol extinction $\left(\mathrm{km}^{-1}\right)$, 2008: (a) $180-135^{\circ} \mathrm{W}$, MAM; (b) $75-40^{\circ} \mathrm{W}$, JJA; (c) $15^{\circ} \mathrm{W}-30^{\circ} \mathrm{E}$, JJA; (d) $70-90^{\circ} \mathrm{E}$, JJA.

Guinea. By JJA the burning has moved south and smoke is transported westward into the southeast Atlantic, west of Angola, at altitudes typically above $2 \mathrm{~km}$. Scale heights in southern Africa and in the southeast Atlantic are highest during SON, the peak of the burning season in that region. High altitude outflow, primarily Asian dust, is seen in springtime from East Asia across the North Pacific Ocean. Outflow during summer seems to be confined to the north Pacific west of the international dateline.

Many interesting seasonal features and geographical contrasts can be seen at the regional scale which are not evident in the global zonal mean (Fig. 6). Figure 11 shows seasonal zonal mean extinction profiles for four different longitude bands during 2008. Figure 11a corresponds to the midPacific Ocean, except for north of 60 degrees which falls over Alaska, during MAM. The majority of the aerosol is confined to the marine boundary layer (MBL), with an apparent top between $500 \mathrm{~m}$ and $1 \mathrm{~km}$. Low average concentrations of aerosol are seen extending above $5 \mathrm{~km}$ north of $40^{\circ} \mathrm{N}$ corresponding to the transport of aerosol from Asia, primarily desert dust. This feature is not apparent in other seasons. High aerosol loading is seen in the southern ocean, $40-60^{\circ} \mathrm{S}$, and this is a persistent feature in all seasons. Aerosol within the MBL appears generally to be well-mixed in the vertical. Between the equator and $20^{\circ} \mathrm{S}$, however, extinction is highest at the top of the MBL and decreases toward the surface. This appears to be a feature related to local meteorology. A similar feature is present in DJF, but the MBL profile is mostly uniform in JJA and SON which, however, have a similar extinction gradient around $20-30^{\circ} \mathrm{N}$.

Figure 11b shows data from JJA covering most of South America and the eastern Caribbean. Significant aerosol concentrations extend above $2 \mathrm{~km}$ between the equator and $20^{\circ} \mathrm{S}$, corresponding to central Brazil. Aerosol concentrations are even larger here during SON, the peak of the South American biomass burning season (not shown), and extend even higher, but are suppressed during the other two seasons. Aerosol in the northern tropics is dominated by Saharan dust. This feature shows up most prominently in JJA. The vertical extent is less in MAM and DJF, and is virtually absent in SON.

Figure 11c shows data from JJA covering Africa and most of Europe. Aerosol extends to high altitudes on both sides of the equator, with Sahara dust to the north and smoke from biomass burning to the south, and deep tropical convection in between. The dust and smoke features vary in strength by season (not shown). In southern mid-latitudes, $40-60^{\circ} \mathrm{S}$, high aerosol concentrations are again seen in the shallow MBL.

Figure 11d shows data from JJA covering the Indian Ocean, most of India, and western China. The Himalayas and the Tibetan Plateau are located between about $30^{\circ} \mathrm{N}$ and $40^{\circ} \mathrm{N}$ and a large contrast in aerosol concentration can be seen between India, to the south, and China to the north. There is also a large contrast between northern and southern Indian Ocean. Aerosol is transported from India southward into the Indian Ocean, but only to about the equator, and the Indian Ocean in the Southern Hemisphere is much cleaner. This is consistent with previous studies.

CALIOP is providing the first observations of wintertime aerosol distributions across the Arctic. Figure 12 shows the multi-year mean AOD for DJF. Higher aerosol loadings are seen on the Russian side of the Arctic than the Canadian, consistent with the location of aerosol sources and mean surface winds during Arctic winter (DeWeaver and Bitz, 2006). Typical background aerosol levels in the Arctic fall below the detection limit of the CALIOP retrieval algorithm. Thus the CALIOP aerosol record corresponds primarily to the occurrence of enhanced aerosol loadings. The main mechanism responsible for aerosols observed during DJF over the frozen Arctic Ocean is the transport of pollution resulting from industrial activities, heating, and other sources of fossil fuel 


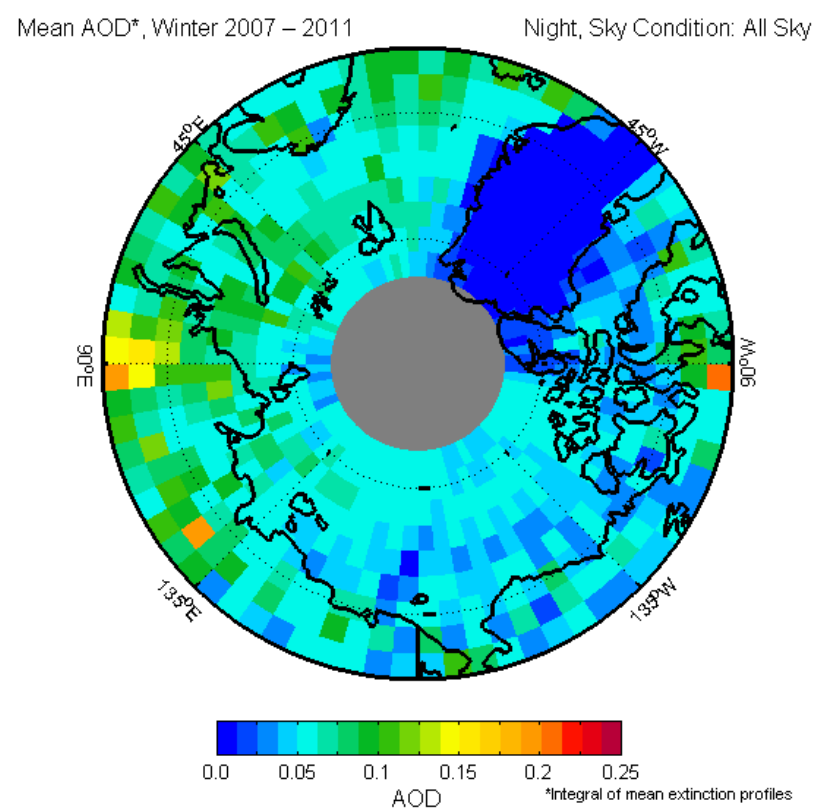

Fig. 12. Mean $532 \mathrm{~nm}$ AOD in the Arctic, DJF 2007-2011, nighttime.

combustion. Most of these effective sources are at high latitudes, in Russia and Scandinavia, as transport from lower latitudes is inhibited by the Arctic front (Stohl, 2006).

Figure 13 shows multi-year monthly mean Arctic profiles for $61-82^{\circ} \mathrm{N}$ for January and March. Only nighttime observations are used here to avoid aliasing detection sensitivity and seasonal aerosol variability. The aerosol is seen to be confined to the lowest kilometer of the atmosphere during January while during March, the beginning of the classic "Arctic haze" season, aerosol loading above $2 \mathrm{~km}$ altitude is significantly enhanced relative to January. The sudden decrease of extinction just above the surface, which can also be seen in Figs. 8 and 17, is unrealistic and has recently been traced to an instrument artifact producing occasional large negative signals just above the Earth surface. A correction for this effect is being developed, which will be applied in future data releases. The mean AOD is similar for the two months, but extinction near the surface is higher in January than March.

\section{Comparison against independent observations}

The discussion above has shown the patterns of aerosol geographic and vertical distribution revealed by CALIOP are reasonable and consistent with our current understanding of aerosol sources and transport. It is important to quantitatively evaluate the accuracy of any data product by comparison with independent measurements, but this is difficult to do with a global aerosol profile product. The Aeronet network of multiwavelength sunphotometers (Holben et al., 2001) has
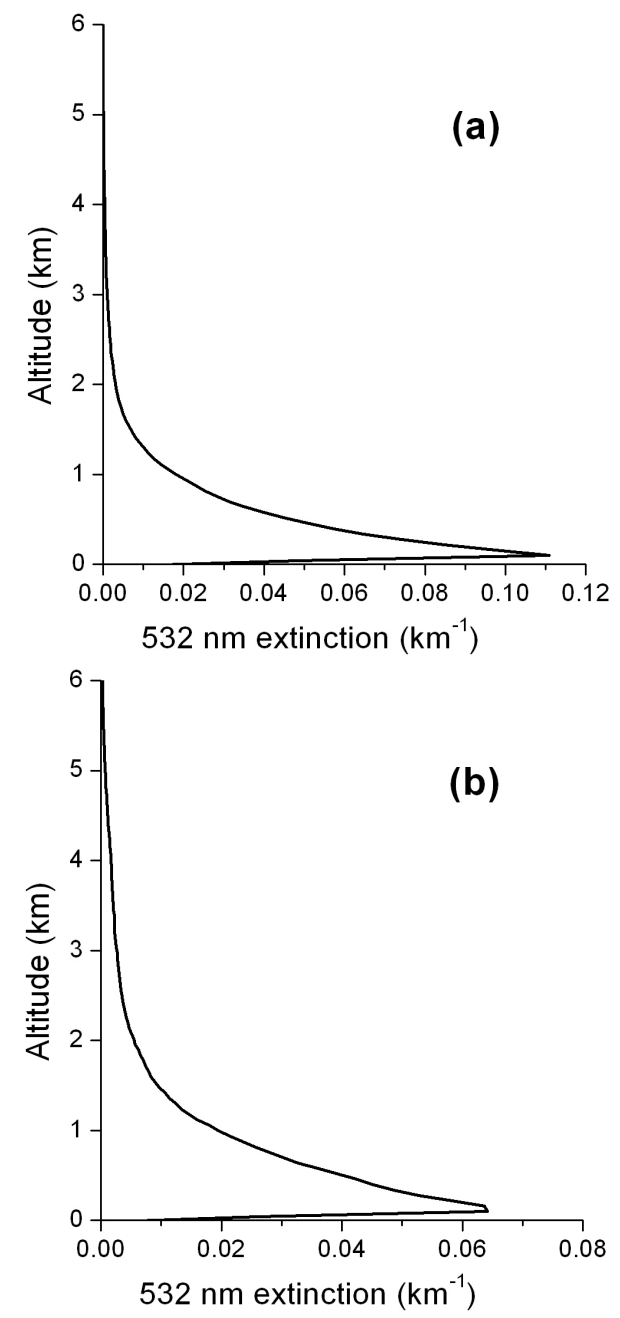

Fig. 13. Monthly-mean Arctic profiles, $61-82^{\circ} \mathrm{N}$, night only. (a) January 2007-2011; (b) March 2007-2011.

been invaluable for validation of global AOD from MODIS and other satellite sensors, providing easy on-line access to multi-year datasets from hundreds of instruments spread around the globe, including all seven continents. There is nothing equivalent for aerosol profile data, however. Several quasi-operational lidar networks exist, including Earlinet (http://www.earlinet.org/) and MPLnet (http://mplnet. gsfc.nasa.gov/), but global coverage is very sparse. Additionally, there is a large diversity in the instruments used and in the characteristics and quality of the datasets. Therefore, substantial effort is required to obtain and use the data. The following discussion is an initial quantitative exploration of accuracy and limitations of the CALIOP profile data and more comprehensive activities are underway to validate the CALIOP aerosol extinction products.

A recent paper (Omar et al., 2013) compares CALIOP $532 \mathrm{~nm}$ Level 2 AOD with co-located Aeronet $500 \mathrm{~nm}$ AOD, primary over land and in coastal regions, where most of the 


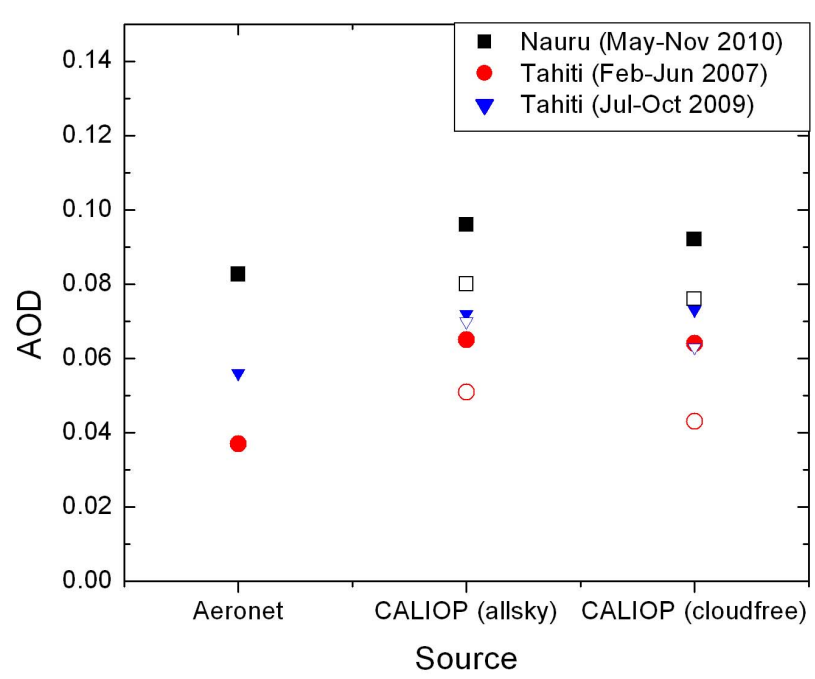

Fig. 14. Comparison of seasonally averaged Aeronet and CALIOP AOD data in two clean marine regions.

Aeronet stations are located. A tendency was noted, based mostly on continental sites, that CALIOP underestimates AOD when AOD is on the order of 0.05 or lower. This was attributed primarily to a failure to detect weak aerosol layers. This raises a concern over potential bias of CALIOP AOD in clean ocean regions, where AOD is typically less than 0.1 (Smirnov et al., 2002). The Omar et al. (2013) study was based on co-located comparisons with Aeronet when the CALIOP measurements fell within $40 \mathrm{~km}$. This requirement excluded all Aeronet sites in pristine marine environments. Therefore, here we compare long-term averages from a few Aeronet sites in the remote Pacific Ocean with regional monthly-mean CALIOP AOD over the same time period. Data was selected during seasons when measurements from the island Aeronet stations were likely to be representative of a large region. CALIOP AOD was averaged over a region surrounding the Aeronet site which appeared to be homogeneous in AOD and over the same months that the Aeronet measurements were acquired. Results are shown in Fig. 14 for 2 locations, Tahiti and Nauru, which can be considered clean marine locations. It is seen that all four versions of CALIOP AOD agree well with Aeronet. There is no evidence that CALIOP underestimates marine AOD in clean conditions. Instead, there seems to be a slight positive bias of about 0.02 .

CALIOP is recognized as a valuable tool for evaluating the performance of global aerosol models. A major concern which has been noted in studies comparing CALIOP profiles to estimates from global aerosol models (Yu et al., 2010; Koffi et al., 2012) is significant discrepancies in the free troposphere, with models generally predicting larger aerosol concentrations than observed by CALIOP. The detection thresholds used in the standard CALIOP retrieval algorithm cause low concentrations of aerosol to be missed. This is

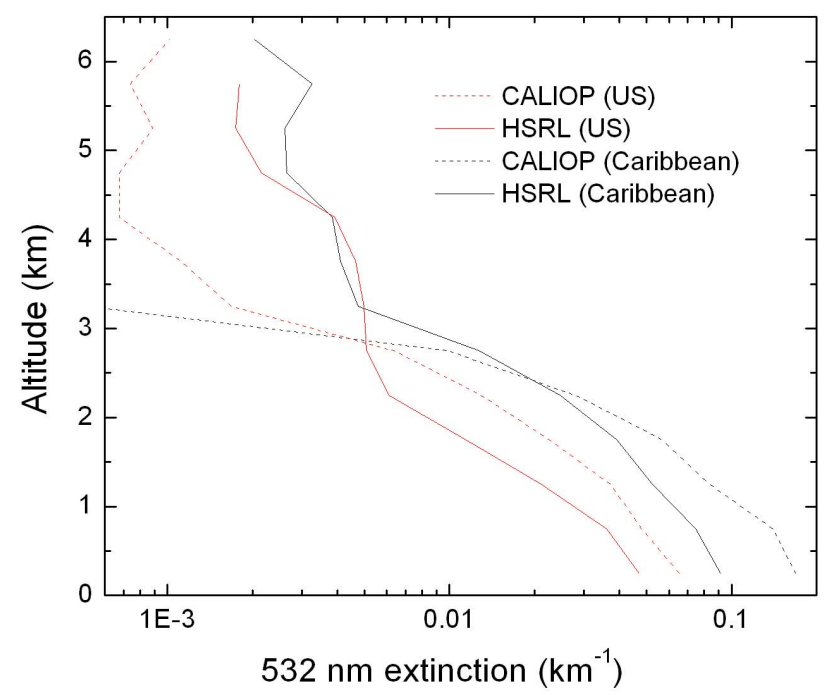

Fig. 15. Co-located HSRL and CALIOP nighttime $532 \mathrm{~nm}$ extinction profiles.

a particular concern in the free troposphere, where aerosol loading often falls below the CALIOP detection threshold. As mentioned above, regions of "clear air" where no aerosol is detected are assigned an extinction of $0.0 \mathrm{~km}^{-1}$ so the Level 3 mean profiles represent a lower limit on the aerosol loading. If the aerosol extinction in regions where no aerosol is detected is very low, then the assumption of zero extinction is a good approximation. On the other hand, if the aerosol concentration is just below the detection limit then the averaged profiles may be significantly underestimated and questions arise as to the magnitude of the underestimate. We examine this issue by comparing with several different independent datasets.

It is difficult to find independent datasets with which to evaluate the accuracy of CALIOP monthly-mean aerosol profiles. A large dataset of co-located high spectral resolution lidar (HSRL) measurements of $532 \mathrm{~nm}$ aerosol extinction is available over North America and the eastern Caribbean (Hair et al., 2008; Rogers et al., 2011). Acquired during a series of more than 100 underflights of the CALIPSO satellite, this represents the most accurate and most comprehensive dataset available for comparison. The HSRL operates on a King Air turboprop aircraft in downlooking mode and typically provides profiles from the surface to 6 or $7 \mathrm{~km}$ altitude. The HSRL $532 \mathrm{~nm}$ aerosol extinction is believed to be accurate to about $0.001 \mathrm{~km}^{-1}$, limited by stability of the detector channel gains (J. Hair, personal communication, 2012). Figure 15 shows the average of nighttime HSRL profiles collected during CALIPSO underflights in the eastern Caribbean, during August 2010, and over southeast US and the US mid-Atlantic region, mostly during winter and spring seasons, together with CALIOP extinction profiles averaged along the same flight tracks. HSRL profiles show the 
mixed layer to be somewhat deeper over the eastern US than in the Caribbean, but average aerosol extinction measured by HSRL above $4 \mathrm{~km}$ altitude is similar in both locations, about $0.002-0.003 \mathrm{~km}^{-1}$. CALIOP appears to be adequately detecting aerosol for mean extinctions greater than $0.005-$ $0.01 \mathrm{~km}^{-1}$, although extinction is overestimated below $3 \mathrm{~km}$. The CALIOP profiles underestimate aerosol extinction above $4 \mathrm{~km}$ by about $0.002 \mathrm{~km}^{-1}$, however. A similar result is reported in Sheridan et al. (2012), based on co-located airborne in situ extinction measurements. Aerosol in the southeast US is most often classified as Polluted Continental or Smoke and the most likely reason for the CALIOP overestimate is that the lidar ratios used for these two aerosol types are too large for the aerosol typically found in the southeast US. Overestimated extinction in the Caribbean MBL is consistent with other comparisons and may be due to selecting inappropriate lidar ratios for mixtures of desert dust and marine aerosol.

Aerosol loading observed in the eastern United States or the eastern Caribbean cannot be assumed to be representative of conditions in other locations, however, and we must turn to other data sources to get a more global view of aerosol loading in the free troposphere. Clarke and Kapustin (2002) summarize in situ aerosol measurements collected on several airborne campaigns during the 1990's covering much of the Pacific basin and parts of North America. While most of the measurements were acquired in the Pacific Ocean tropics and subtropics, data was acquired over the Pacific from $65^{\circ} \mathrm{S}$ to $60^{\circ} \mathrm{N}$. This dataset thus represents a reasonably comprehensive survey of aerosol in the free troposphere above remote ocean. They found that aerosol $550 \mathrm{~nm}$ light scattering above $3 \mathrm{~km}$, measured with a TSI 3560 nephelometer, varied typically from $1 \mathrm{E}-4 \mathrm{~km}^{-1}$ to $1 \mathrm{E}-3 \mathrm{~km}^{-1}$ in "background" conditions and from 0.001 to $0.01 \mathrm{~km}^{-1}$ when layers of continental origin were encountered.

A global climatology of aerosol extinction in the upper troposphere for the period 1989-1996 was developed by Kent et al. (1998) using solar occultation data from the SAGE II satellite sensor. These measurements are derived from observations along a tangent path through the atmosphere, typically representing averages over paths of $300 \mathrm{~km}$. Thus the SAGE results represent average aerosol loading at a scale of a few hundred kilometers. The average lower limit on aerosol extinction between $6-9 \mathrm{~km}$ altitude was found to be about $0.001 \mathrm{~km}^{-1}$ at $525 \mathrm{~nm}$, significantly larger than the lowest values measured in situ by Clarke and Kapustin (2002). The difference may be due to the SAGE tangent path averaging the cleanest regions together with atmospheric volumes with higher aerosol loading, or it could be due to imperfect cloud clearing by the SAGE retrieval algorithm.

To further evaluate potential low biases in the upper troposphere, CALIOP monthly mean profiles were compared with the results of full-column retrievals. Four regions, shown in Fig. 16, were selected for comparison of seasonal mean profiles. Regions and seasons were selected for diversity in aerosol type and vertical distributions. The primary objective

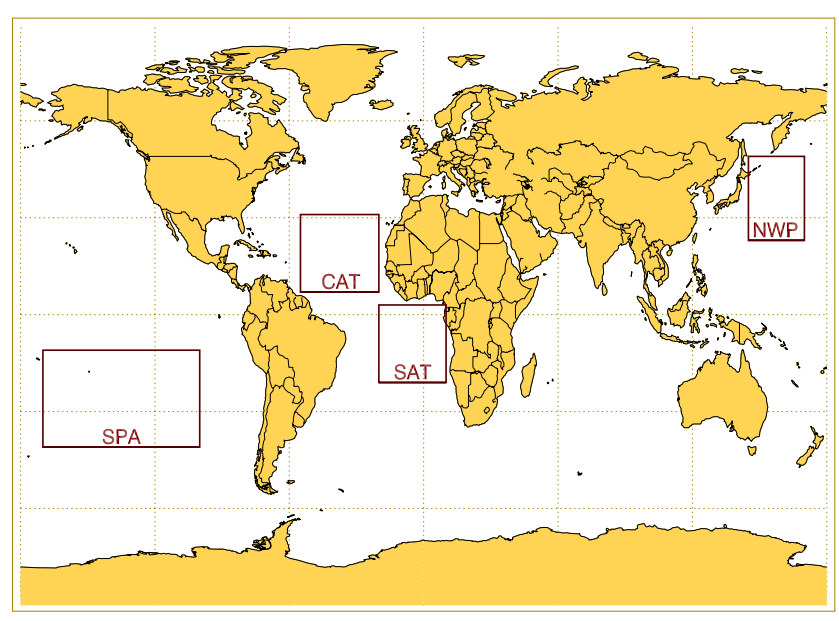

Fig. 16. Four regional study areas.

was to use the full-column retrievals to evaluate the representivity of the Level 3 aerosol extinction profiles in the upper troposphere and to put bounds on the magnitude of any low bias.

Extinction retrievals in the upper troposphere are sensitive to calibration error when aerosol extinction is very low. Therefore the CALIOP Level 1 profiles were first recalibrated, using the approach of Vernier et al. (2009) to correct calibration biases due to stratospheric aerosol not accounted for in the Version 3 calibration algorithm. The CALIOP Vertical Feature Mask was used to identify cloud-free $532 \mathrm{~nm}$ Level 1 profiles, which were then averaged horizontally over $5 \mathrm{~km}$ to improve SNR. A two-component retrieval (Fernald, 1984), explicitly considering molecular and particulate scattering, was performed starting at $12 \mathrm{~km}$ and carried down to the surface using a constant aerosol lidar ratio (invariant with height).

The full-column retrievals were performed using constant lidar ratios of $30,40,50$, and $60 \mathrm{sr}$, to span the range of lidar ratios expected in the free troposphere. Because attenuation is small, the retrieved aerosol extinction is proportional to the assumed lidar ratio. If the assumed lidar ratio is too large, the retrieved extinction is overestimated and in some cases becomes unstable and approaches infinity. Therefore, if the retrieved extinction becomes larger than $10 \mathrm{~km}^{-1}$, that range bin and all lower range bins in the profile are removed before averaging. This usually happens only when the assumed lidar ratio is significantly larger than the true lidar ratio.

The CAT, SAT, and NWP regions are characterized by elevated smoke and/or dust layers. Dust is expected to have lidar ratios of about $40 \mathrm{sr}$ (Omar et al., 2010; Burton et al., 2012). Lidar ratios of smoke are expected to be significantly larger, in the range of 50-80 sr. Thus we can expect retrievals using $\mathrm{Sa}=60 \mathrm{sr}$ to be realistic in regions dominated by smoke but to overestimate extinction in regions dominated by dust, where retrievals using $\mathrm{Sa}=40 \mathrm{sr}$ should be more realistic. 

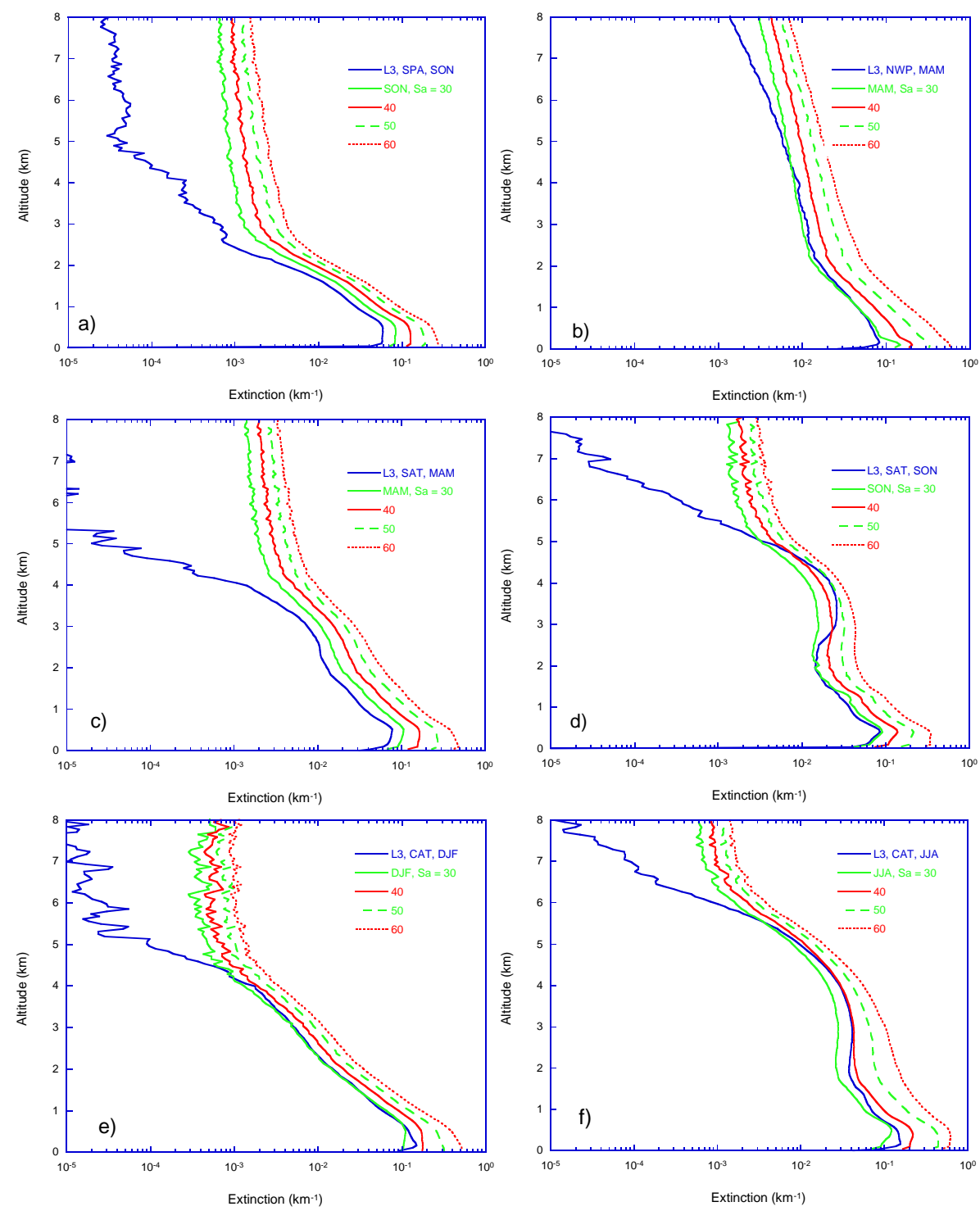

Fig. 17. Comparison of aerosol profiles derived from CALIOP Level 2 data with profiles from full-column retrievals using fixed lidar ratios of 30, 40, 50, and 60 sr. (a) SPA, SON; (b) NWP, MAM; (c) SAT, MAM; (d) SAT, SON; (e) CAT, DJF; (f) CAT, JJA.

Marine aerosol has lidar ratios in the range of 20-25 sr (Omar et al., 2009; Burton et al., 2012) so all of the full-column retrievals shown here are expected to overestimate the true aerosol extinction in clean marine conditions. In the following discussion "FC- $n$ " refers to results derived from fullcolumn retrievals using a constant lidar ratio of " $n$ ".

SPA is a remote region in the southeast Pacific Ocean with little continental influence. We expect most of the aerosol to be confined within the marine boundary layer with lidar ratios in the range of 20-25 sr. We expect the free troposphere to be dominated by fine mode aerosol with extinction near background levels: $0.0001 \mathrm{~km}^{-1}$ to $0.001 \mathrm{~km}^{-1}$, as reported in Clarke and Kapustin (2002). Kent et al. (1998) estimated lidar ratios of 50 to $80 \mathrm{sr}$ at altitudes above $6 \mathrm{~km}$ in the South- ern Hemisphere, consistent with expectations for fine mode aerosol.

The results shown in Fig. 14 show that AOD derived from the Level 3 profiles in clean marine regions somewhat overestimates AOD from Aeronet. In the SPA region during SON (Fig. 17a), we find the FC profiles overestimate extinction in the marine boundary layer (below $1 \mathrm{~km}$ ) relative to Level 3 . This is expected as the lidar ratio used for the FC retrievals is unrealistically large for marine aerosol. Above $2 \mathrm{~km}$ the Level 3 extinction decreases rapidly while the FC retrievals fall off slowly with increasing altitude and imply an aerosol mixing ratio which is constant with altitude. The FC profiles are well above background values measured by Clarke and Kapustin (2002), however. If the backscattering 
from aerosol is much less than that due to the molecular atmosphere, the retrieved aerosol extinction is approximately $\hat{\sigma_{a}}(z)=\beta_{\mathrm{m}}(z) S_{\mathrm{a}} \epsilon$ where $\beta_{\mathrm{m}}$ is the molecular backscatter coefficient, $S_{\mathrm{a}}$ is the assumed lidar ratio, and $\epsilon$ is the fractional calibration error. The behavior of the FC profiles is consistent with calibration errors of a few percent. We consider the magnitude of the FC profiles in the clean upper troposphere is likely driven by calibration error and is not representative of the true aerosol loading. It probably represents an upper bound on the true aerosol extinction, however.

Springtime in the northwest Pacific (NWP) is characterized by long-range transport of aerosol from Asia. Synopticscale lifting can elevate aerosol, primarily dust but perhaps also some smoke and anthropogenic aerosol, to high altitudes. We expect $S_{\mathrm{a}}=40 \mathrm{sr}$ if the layer is dominated by dust. Enhanced aerosol loading is seen up to $8 \mathrm{~km}$ (Fig. 17b). Above $1 \mathrm{~km}$, the shape of the Level 3 profile is similar to the FC profiles up to about $4 \mathrm{~km}$ but then decreases more quickly. At $4 \mathrm{~km}$, the Level 3 profile is about $25 \%$ lower than FC-40, underestimating FC- 40 by $0.003 \mathrm{~km}^{-1}$. Above $5 \mathrm{~km}$ the underestimate of the Level 3 profile relative to FC-40 remains about $0.003 \mathrm{~km}^{-1}$ but becomes more significant in a relative sense.

In the southeastern Atlantic (SAT) enhanced aerosol loading is seen up to about $4 \mathrm{~km}$ during MAM (Fig. 17c) due to transport of aerosol, primarily smoke, from Africa. Aerosol extinction aloft is much larger during SON (Fig. 17d), the primary burning season in southern Africa. During SON, elevated smoke is seen between $3-5 \mathrm{~km}$ where the Level 3 profile agrees well with FC-50 but underestimates extinction somewhat if we believe the smoke lidar ratio should be around $60 \mathrm{sr}$. Above $5 \mathrm{~km}$, the Level 3 profile decreases rapidly relative to the $\mathrm{FC}$ profiles. Below $3 \mathrm{~km}$ we expect mixtures of smoke and marine aerosol, which likely explains the differences in profile shapes between Level 3 and the FC retrievals. During MAM, however, the Level 3 extinction profile is significantly lower than any of the FC retrievals in the region of transported smoke $(2-4 \mathrm{~km})$. This is likely due to lower concentrations of elevated smoke relative to SON which are not detected as frequently by the CALIOP retrieval algorithm.

The central Atlantic Ocean (CAT) is heavily influenced by the transport of dust from Africa. During DJF the dust tends to be found at low altitudes (Fig. 17e), while during JJA it tends to be found in elevated layers above $2 \mathrm{~km}$ altitude and extending as high as 5-6 km (Fig. 17f). The Level 3 and FC profile shapes are quite consistent for both DJF and JJA. During DJF, Level 3 profiles are consistent with FC-30. During JJA the Level 3 profile agrees well with FC-40 between $2 \mathrm{~km}$ and $5 \mathrm{~km}$.

The results shown in Fig. 17, while preliminary, indicate the Level 3 monthly gridded profiles provide quantitative characterization of elevated aerosol layers in major transport pathways such as Sahara dust westward across the subtropical Atlantic, smoke from African biomass burning westward into the south Atlantic, and Asian dust and smoke eastward into the north Pacific. The tops of the elevated plumes in the SAT and CAT extend to altitudes of 4-6 km, consistent with the depth of the mixed layers over the continental regions where these plumes originate, as can be observed in CALIOP Level 2 profiles. The Level 3 profiles generally underestimate free troposphere aerosol loading in clean conditions, where we expect the true aerosol extinction to be typically $0.001 \mathrm{~km}^{-1}$ or less. The NWP MAM and SAT MAM cases, characterized by tenuous layers of dust or smoke at high altitudes which fall somewhat below the CALIOP detection threshold, illustrate conditions where the CALIOP low-bias in the free troposphere can exceed $0.001 \mathrm{~km}^{-1}$. Even in the NWP MAM case, however, the low bias in Level 3 profiles is no more than about $0.003 \mathrm{~km}^{-1}$.

\section{Conclusions}

CALIOP has provided the first systematic measurements of the global 3-D distribution of tropospheric aerosol. While the CALIOP retrieval of aerosol extinction is subject to several limitations, monthly-mean gridded AOD and aerosol extinction profiles appear to be realistic and representative, and a comprehensive view of the global aerosol emerges from the observations. Due to detection limits of the CALIOP Level 2 retrieval algorithm, magnitudes of aerosol extinction retrieved in the upper troposphere may be underestimated. Major aerosol transport pathways such as Sahara dust westward across the subtropical Atlantic, smoke from African biomass burning westward into the south Atlantic, and Asian dust and smoke eastward into the north Pacific are captured quantitatively. As aerosol loading decreases, representivity of the CALIOP observations becomes problematic, however. Validation to better quantify errors and uncertainties is an ongoing activity. We plan to further develop CALIOP retrievals of the full atmospheric column to provide a more accurate picture of aerosol loading in the upper troposphere, but ultimate limits to retrieval performance are set by calibration accuracy. CALIOP Level 3 Aerosol Profile data are available from the NASA Langley Atmospheric Sciences Data Center.

\section{Appendix A}

Several quality control procedures are applied before averaging the profile data. This appendix is added to document the method in detail for those wishing to duplicate our results or to compare with their own. Quality flags embedded in the Level 2 aerosol products are used to remove bad or highly uncertain aerosol extinction data. Additional tests are applied to remove several known artifacts. The more important ones are summarized below. Additional information can be found in the on-line data quality summaries archived at the Langley ASDC. 


\section{A1 CAD_Score}

To avoid aerosol layers which might be the result of detection artifacts, we accept only layers with Cloud Aerosol Discrimination scores inclusive of -100 to -20 . A special CAD score of -101 is used to indicate a layer has positive integrated backscatter but negative average backscatter. Retrieved optical properties are likely to be incorrect in this case and these are screened out.

\section{A2 Ext_QC}

The Extinction_QC flag indicates the type and outcome of the extinction retrieval performed on each layer. We have accepted values of $0,1,18$ and 16 . Values of " 0 " and " 1 " indicating unconstrained and constrained retrievals, respectively (Young and Vaughan, 2009), although constrained retrievals are very rare for aerosol retrievals. Ext_QC values of 0 and 16 correspond to retrievals of semitransparent and opaque layers (respectively) where the initial lidar ratio remains unchanged. A value of 18 indicates an opaque layer where the solution using the initial lidar ratio diverges and the lidar ratio is then decreased to allow a solution. Values of 2, indicating a semitransparent layer where the initial lidar ratio is changed, are rejected. The justification is that adjustment of the initial lidar ratio in the retrieval of semitransparent aerosol layers is not required unless the error in the initial lidar ratio is very large. Adjustment of the initial lidar ratio indicates an error in the aerosol type classification and the retrieval should be rejected as having large uncertainty.

\section{A3 Uncertainty flag}

An uncertainty is computed for each aerosol extinction value. The extinction retrieval starts at the top of the atmosphere and proceeds iteratively downward layer by layer (Young and Vaughan, 2009). A propagated extinction uncertainty estimate is computed at each step, along with the extinction value (Young et al., 2013). Under some conditions the uncertainty estimate diverges and becomes unstable during the iteration. When this happens, the retrieval is considered to have failed and all range bins within the layer are assigned an uncertainty of $99.9 \mathrm{~km}^{-1}$. AOD values for columns containing uncertainties of $99.9 \mathrm{~km}^{-1}$ should therefore be excluded from analysis. In columns containing multiple layers, however, profiles above the layer where the retrieval failed are not impacted. Therefore, when screening aerosol extinction data, range bins with uncertainty of $99.9 \mathrm{~km}^{-1}$ and all extinction values at lower altitudes in the profile are rejected while retaining extinction values at higher altitudes.

\section{A4 CAD artifacts in the upper troposphere}

Weakly scattering edges of ice clouds are sometimes misclassified as aerosol by the CAD algorithm, producing anomalous enhancements of aerosol loading in the upper tropo- sphere. Single aerosol layers occurring in isolation but adjacent to ice clouds are assumed to be misclassified cloud and are ignored. This test is applied only to aerosol layers with bases above $4 \mathrm{~km}$ and adjacent to cloud layers identified as ice with top temperatures less than $0^{\circ} \mathrm{C}$. At high latitudes ice clouds can be found down to the surface, but cloud adjacency issues tend to be found at higher altitudes.

\section{A5 Noise spikes}

Noise spikes occasionally occur which result in the spurious detection of $80-\mathrm{km}$ aerosol layers. These layers are prominent when they occur in the upper troposphere, where few aerosol layers are detected. This happens infrequently and, in any case, has negligible effect on column AOD, but can influence the average profile in the upper troposphere where aerosol detection is rare.

\section{A6 Negative extinction}

Negative extinction values can occur due to noise excursions. Systematic large negative extinction values occasionally occur near the surface due to either surface contamination or instrument characteristics. Therefore, extinction values near the surface less than $-0.2 \mathrm{~km}^{-1}$ are ignored.

Acknowledgements. This research was supported by the NASA Earth Science Enterprise. We thank the Aeronet program and the many Aeronet PIs and site managers who make the Aeronet program possible, and the NASA Langley HSRL team for their dedication in acquiring such a comprehensive dataset coincident with CALIPSO.

Edited by: D. Tanre

\section{References}

Burton, S. P., Ferrare, R. A., Hostetler, C. A., Hair, J. W., Rogers, R. R., Obland, M. D., Butler, C. F., Cook, A. L., Harper, D. B., and Froyd, K. D.: Aerosol classification using airborne High Spectral Resolution Lidar measurements - methodology and examples, Atmos. Meas. Tech., 5, 73-98, doi:10.5194/amt-5-73-2012, 2012.

Chin, M., Ginoux, P., Kinne, S., Torres, O., Holben, B. N., Duncan, B. N., Martin, R. V., Logan, J. A., Higurashi, A., and Nakajima, T.: Tropospheric Aerosol Optical Thickness from the GOCART Model and Comparisons with satellite and Sun photometer Measurements, J. Atmos. Sci., 59, 461-483, 2002.

Clarke, A. D. and Kapustin, V. N.: A Pacific aerosol survey. Part I: A decade of data on particle production, transport, evolution, and mixing in the troposphere, J. Atmos. Sci., 59, 363-382, 2002.

DeWeaver, E. and Bitz, C. M.: Atmospheric Circulation and Its Effect on Arctic Sea Ice in CCSM3 Simulations at Medium and High Resolution, J. Climate, 19, 2415-2436, 2006.

Fernald, F. G.: Analysis of atmospheric lidar observations: some comments, Appl. Opt., 23, 652-653, 1984. 
Hair, J. W., Hostetler, C. A., Cook, A. L., Harper, D. B., Ferrare, R. A., Mack, T. L., Welch, W., Izquierdo, L. R., and Hovis, F. E.: Airborne High Spectral Resolution lidar for profiling aerosol optical properties, Appl. Opt., 47, 6734-6752, 2008.

Holben, B. N., Tanre, D., Smirnov, A., Eck, T. F., Slutsker, I., Abuhassan, N., Newcomb, W. W., Schafer, J. S., Chatenet, B., Lavenu, F., Kaufman, Y. J., vande Castle, J., Setzer, A., Markham, B., Clark, D., Frouin, R., Halthore, R., Karneli, A., O'Neill, N. T., Pietras, C., Pinker, R. T., Voss, K., and Zibordi, G.: An emerging ground based aerosol climatology: Aerosol optical depth from AERONET, J. Geophys. Res., 106, 1206712097, 2001.

Huneeus, N., Schulz, M., Balkanski, Y., Griesfeller, J., Prospero, J., Kinne, S., Bauer, S., Boucher, O., Chin, M., Dentener, F., Diehl, T., Easter, R., Fillmore, D., Ghan, S., Ginoux, P., Grini, A., Horowitz, L., Koch, D., Krol, M. C., Landing, W., Liu, X., Mahowald, N., Miller, R., Morcrette, J.-J., Myhre, G., Penner, J., Perlwitz, J., Stier, P., Takemura, T., and Zender, C. S.: Global dust model intercomparison in AeroCom phase I, Atmos. Chem. Phys., 11, 7781-7816, doi:10.5194/acp-11-7781-2011, 2011.

Husar, R. B., Prospero, J. M., and Stowe, L. L.: Characterization of tropospheric aerosols over the oceans with the NOAA advanced very high resolution radiometer optical thickness operational product, J. Geophys. Res., 102, 16889-16909, 1997.

Kent, G. S., Trepte, C. R., Skeens, K. M., and Winker, D. M.: LITE and SAGE II measurements of aerosols in the southern hemisphere upper troposphere, J. Geophys. Res., 103, 19111-19127, 1998.

Kinne, S., Schulz, M., Textor, C., Guibert, S., Balkanski, Y., Bauer, S. E., Berntsen, T., Berglen, T. F., Boucher, O., Chin, M., Collins, W., Dentener, F., Diehl, T., Easter, R., Feichter, J., Fillmore, D., Ghan, S., Ginoux, P., Gong, S., Grini, A., Hendricks, J., Herzog, M., Horowitz, L., Isaksen, I., Iversen, T., Kirkevåg, A., Kloster, S., Koch, D., Kristjansson, J. E., Krol, M., Lauer, A., Lamarque, J. F., Lesins, G., Liu, X., Lohmann, U., Montanaro, V., Myhre, G., Penner, J., Pitari, G., Reddy, S., Seland, O., Stier, P., Takemura, T., and Tie, X.: An AeroCom initial assessment - optical properties in aerosol component modules of global models, Atmos. Chem. Phys., 6, 1815-1834, doi:10.5194/acp-6-1815-2006, 2006.

Kittaka, C., Winker, D. M., Vaughan, M. A., Omar, A., and Remer, L. A.: Intercomparison of column aerosol optical depths from CALIPSO and MODIS-Aqua, Atmos. Meas. Tech., 4, 131-141, doi:10.5194/amt-4-131-2011, 2011.

Koffi, B.,Schulz, M., Bréon, F.-M., Griesfeller, J., Winker, D., Balkanski, Y., Bauer, S., Berntsen, T., Chin, M., Collins, W. D., Frank Dentener, F., Diehl, T., Easter, R., Steven Ghan, S., Ginoux, P., Gong, S., Horowitz, L.W., Iversen, T., Kirkevåg, A., Koch, D., Krol, M., Myhre, G., Stier, P., and Takemura, T.: Application of the CALIOP layer product to evaluate the vertical distribution of aerosols estimated by global models: AeroCom phase I results, J. Geophys. Res., 117, doi:10.1029/2011JD016858, 2012.

Levy, R. C., Leptoukh, G. G., Kahn, R., Zubko, V., Gopalan, A., and Remer, L. A.: A Critical Look at Deriving Monthly Aerosol Optical Depth From Satellite Data, IEEE Trans. Geosci. Rem. Sens., 47, 2942-2956, doi:10.1109/TGRS.2009.2013842, 2009.

Liu, Z., Omar, A., Vaughan, M., Hair, J., Kittaka, C., Hu, Y., Powell, K., Trepte, C., Winker, D., Hostetler, C., Ferrare, R., and Pierce,
R.: CALIPSO lidar observations of the optical properties of Saharan dust: A case study of long-range transport, J. Geophys. Res., 113, D07207, doi:10.1029/2007JD008878, 2008.

Liu, Z., Vaughan, M. A., Winker, D. M., Kittaka, C., Getzewich, B. J., Kuehn, R. E., Omar, A., Powell, K., Trepte, C. R., and Hostetler, C. A.: The CALIPSO Lidar Cloud and Aerosol Discrimination: Version 2 Algorithm and Initial Assessment of Performance, J. Atmos. Oceanic Technol., 26, 1198-1213, doi:10.1175/2009JTECHA1229.1, 2009.

Loeb, N. G. and Manolo-Smith, N.: Top-of-Atmosphere Direct Radiative Effect of Aerosols over Global Oceans from Merged CERES and MODIS Observations, J. Climate, 18, 3506-3526, 2005.

Omar, A., Winker, D., Kittaka, C., Vaughan, M., Liu, Z., Hu, Y., Trepte, C., Rogers, R., Ferrare, R., Kuehn, R., and Hostetler, C.: The CALIPSO Automated Aerosol Classification and Lidar Ratio Selection Algorithm, J. Atmos. Oceanic Technol., 26, 19942014, doi:10.1175/2009JTECHA1231.1, 2009.

Omar, A., Liu, Z., Vaughan, M., Thornhill, K. L. , Kittaka, C., Ismail, S., Hu, Y., Chen, G., Winker, D., Trepte, C., Winstead, E. L., and Anderson, B. E: Extinction-to-backscatter ratios of Saharan dust layers derived from in situ measurements and CALIPSO overflights during NAMMA, J. Geophys. Res., 115, D24217, doi:10.1029/2010JD014223, 2010.

Omar, A., Winker, D. M., Tackett, J. L., Kar, J., Liu, Z., Vaughan, M., Powell, K., and Trepte, C.: CALIOP and Aeronet optical depth comparisons, J. Geophys. Res., in press, 2013.

Redemann, J., Vaughan, M. A., Zhang, Q., Shinozuka, Y., Russell, P. B., Livingston, J. M., Kacenelenbogen, M., and Remer, L. A.: The comparison of MODIS-Aqua (C5) and CALIOP (V2 \& V3) aerosol optical depth, Atmos. Chem. Phys., 12, 3025-3043, doi:10.5194/acp-12-3025-2012, 2012.

Remer, L. A., Kleidman, R. G., Levy, R. C., Kaufman, Y. J., Tanre, D., Mattoo, S., Martins, J. V., Ichoku, C., Koren, I., Yu, H., and Holben, B. N.: Global aerosol climatology from the MODIS satellite sensors, J. Geophys. Res., 113, D14S07, doi:10.1029/2007JD009661, 2008.

Rogers, R. R., Hostetler, C. A., Hair, J. W., Ferrare, R. A., Liu, Z., Obland, M. D., Harper, D. B., Cook, A. L., Powell, K. A., Vaughan, M. A., and Winker, D. M.: Assessment of the CALIPSO Lidar $532 \mathrm{~nm}$ attenuated backscatter calibration using the NASA LaRC airborne High Spectral Resolution Lidar, Atmos. Chem. Phys., 11, 1295-1311, doi:10.5194/acp-11-12952011, 2011.

Sheridan, P. J., Andrews, E., Ogren, J. A., Tackett, J. L., and Winker, D. M.: Vertical profiles of aerosol optical properties over central Illinois and comparison with surface and satellite measurements, Atmos. Chem. Phys., 12, 11695-11721, doi:10.5194/acp12-11695-2012, 2012.

Smirnov, A., Holben, B. N., Kaufman, Y. J., Dubovik, O., Eck, T. F., Slutsker, I., Pietras, C., and Halthore, R. N.: Optical properties of atmospheric aerosol in maritime environments, J. Atmos. Sci., 59, 501-523, 2002.

Stohl, A.: Characteristics of atmospheric transport into the Arctic troposphere, J. Geophys. Res., 111, D11306, doi:10.1029/2005JD006888, 2006.

Textor, C., Schulz, M., Guibert, S., Kinne, S., Balkanski, Y., Bauer, S., Berntsen, T., Berglen, T., Boucher, O., Chin, M., Dentener, F., Diehl, T., Easter, R., Feichter, H., Fillmore, D., Ghan, S., Ginoux, 
P., Gong, S., Grini, A., Hendricks, J., Horowitz, L., Huang, P., Isaksen, I., Iversen, I., Kloster, S., Koch, D., Kirkevåg, A., Kristjansson, J. E., Krol, M., Lauer, A., Lamarque, J. F., Liu, X., Montanaro, V., Myhre, G., Penner, J., Pitari, G., Reddy, S., Seland, $\varnothing$., Stier, P., Takemura, T., and Tie, X.: Analysis and quantification of the diversities of aerosol life cycles within AeroCom, Atmos. Chem. Phys., 6, 1777-1813, doi:10.5194/acp-6-1777-2006, 2006.

Vaughan, M. A., Powell, K. A., Kuehn, R. E., Young, S. A., Winker, D. M., Hostetler, C. A., Hunt, W. H., Liu, Z., McGill, M. J., and Getzewich, B. J.: Fully Automated Detection of Cloud and Aerosol Layers in the CALIPSO Lidar Measurements, J. Atmos. Ocean. Tech., 26, 2034-2050, 2009.

Vernier, J. P., Pommereau, J. P., Garnier, A., Pelon, J., Larsen, N., Nielsen, J., Christensen, T., Cairo, F., Thomason, L. W., Leblanc, T., and McDermid, I. S.: Tropical stratospheric aerosol layer from CALIPSO lidar observations, J. Geophys. Res., 114, D00H10, doi:10.1029/2009JD011946, 2009.

Winker, D. M., Vaughan, M. A., Omar, A. H., Hu, Y., Powell, K. A., Liu, Z., Hunt, W. H., and Young, S. A.: Overview of the CALIPSO Mission and CALIOP Data Processing Algorithms, J. Atmos. Oceanic Technol., 26, 2310-2323, 2009.

Winker, D. M., Pelon, J., Coakley Jr., J. A., Ackerman, S. A., Charlson, R. J., Colarco, P. R., Flamant, P., Fu, Q., Hoff, R., Kittaka, C., Kubar, T. L., LeTreut, H., McCormick, M. P., Megie, G., Poole, L., Powell, K., Trepte, C., Vaughan, M. A., and Wielicki, B. A.: The CALIPSO Mission: A Global 3D View Of Aerosols And Clouds, Bull. Amer. Meteor. Soc., 91, 1211-1229, doi:10.1175/2010BAMS3009.1, 2010.
Young, S. A. and Vaughan, M. A.: The retrieval of profiles of particulate extinction from Cloud Aerosol Lidar Infrared Pathfinder Satellite Observations (CALIPSO) data: Algorithm description, J. Atmos. Ocean. Tech., 26, 1105-1119, 2009.

Young, S. A., Vaughan, M. A., Kuehn, R. E., and Winker, D. M.: The Retrieval of Profiles of Particulate Extinction from Cloud-Aerosol Lidar Infrared Pathfinder Satellite Observations (CALIPSO) Data: Uncertainty and Error Sensitivity Analyses, J. Atmos. Oceanic Technol., doi:10.1175/JTECH-D-12-00046.1, in press, 2013.

Yu, H., Chin, M., Winker, D. M., Omar, A. H., Liu, Z., Kittaka, C., and Diehl, T.: Global view of aerosol vertical distributions from CALIPSO lidar measurements and GOCART simulations: Regional and seasonal variations, J. Geophys. Res., 115, D00H30, doi:10.1029/2009JD013364, 2010.

Zhang, J. and Reid, J. S.: MODIS aerosol product analysis for data assimilation: Assessment of over-ocean level 2 aerosol optical thickness retrievals, J. Geophys. Res., 111, D22207, doi:10.1029/2005JD006898, 2006. 